\title{
Geologia
}

\section{Análise das Fraturas nos Basaltos de Ribeirão Preto, SP: Aplicação à Elaboração de Modelo Hidrogeológico Conceitual}

\section{Fracture Analysis of the Ribeirao Preto Basalts, SP: Application for Developing a Conceptual Hydrogeological Model}

\author{
Amélia João Fernandes (ameliajf@ igeologico.sp.gov.br), \\ Carlos Henrique Maldaner ${ }^{2}$ (cmaldaner@gmail.com), Alain Rouleau³ (alain_rouleau@uqac.ca) \\ ${ }^{1}$ Instituto G eológico - SMASP \\ Av. Miguel Stéfano 3.900, CEP 04301-903, São Paulo, SP, BR \\ ${ }^{2}$ Centro de Pesquisas de Águas Subterrâneas - Instituto de Geociências - USP, São Paulo, SP, BR \\ ${ }^{3}$ Université du Q uébec à Chicoutimi - UQ AC, Saguenay, Q uébec, CA \\ Recebido em 29 de março de 2011; aceito em 26 de agosto de 2011
}

\begin{abstract}
RESUMO
A motivação que levou ao estudo da geologia física e química dos basaltos de Ribeirão Preto foi investigar a existência de recarga do Sistema Aquífero Guarani (SAG) através dos basaltos do Aquífero Serra Geral (ASG), objetivo do projeto abreviadamente denominado de FRATASG. Além de métodos hidrogeológicos, a pesquisa demandou uma investigação geológica de detalhe, a qual é essencial para a elaboração de modelos conceituais de circulação de água subterrânea em aquíferos complexos, caso dos basaltos do ASG. Assim, o estudo englobou levantamentos estruturais de detalhe e a análise de fraturas que levou à identificação de quatro eventos tectônicos. Concluiu-se que o fluxo vertical de água subterrânea é importante até a profundidade de $10 \mathrm{~m}$ e, secundariamente, até $25 \mathrm{~m}$. O fluxo horizontal, mais importante até a profundidade de $50 \mathrm{~m}$, ocorre ao longo de fraturas preferencialmente localizadas nos contatos entre os basaltos B2 e B3 ou próximas a estes. Sugere-se que a recarga do SAG através do ASG é dificultada pela não propagação de fraturas nos níveis vesiculares dos basaltos, presentes nos contatos entre derrames, que funcionariam como uma barreira hidráulica de caráter regional. Assim a circulação de água subterrânea nos basaltos é do tipo limitada por estratos (stratabound), uma vez que é muito mais intensa paralelamente aos derrames do que transversalmente a eles. Com base em feições diagnósticas de fluxo, propõe-se que o fluxo vertical, atravessando toda a pilha de basaltos e chegando ao SAG, quando presente, ocorra segundo estruturas de direção NE.
\end{abstract}

Palavras-chave: Formação Serra Geral; Geologia estrutural; Tectônica; Fluxo de água subterrânea; Aquíferos fraturados; Recarga do Sistema Aquífero Guarani.

\begin{abstract}
The study of the physical geology and geochemistry of the Ribeirão Preto basalts was part of a hydrogeological research, which aimed to investigate the recharge of the Guarani Aquifer System (SAG) through the basalts of the Serra Geral Aquifer (ASG), a project shortly named FRATASG. In addition to the hydrogeological research, a detailed geological investigation was conducted to develop a conceptual model of groundwater flow in complex aquifers, as is the case of the fractured basalts of the ASG. Therefore, this study included a thorough structural survey and analysis of horizontal and subvertical fractures, which resulted in the identification of four tectonic events. It was concluded that the vertical groundwater flow is important up to $10 \mathrm{~m}$ in depth and, secondarily, up to $25 \mathrm{~m}$. Horizontal flow, more evident up to the depth of $50 \mathrm{~m}$, predominates and occurs along sub-horizontal fractures, which occur mainly at the contact between basalts 2 and 3 and in its vicinity. Because the great majority of subvertical fractures do not propagate into the vesicular layers, which occur at the basalt contacts, it is suggested that these layers act as regional hydraulic barriers, and greatly hamper the recharge of the SAG through the ASG. As a consequence, groundwater flow in the basalt stack is of stratabound type,
\end{abstract}


as it occurs mainly along the basalt contacts. Based on diagnostic features of the flow, it is proposed in this study that the vertical flow, which crosses the basalt stack reaching the SAG, is local and probably occurs along NE structures.

Keywords: Serra Geral Formation; Structural geology; Tectonics; Groundwater flow; Fractured aquifer; Recharge of the Guarani Aquifer System.

\section{INTRODUÇÃO}

O Instituto Geológico - SMA, em parceria com a USP - Universidade de São Paulo, e com colaboração do USGS - Serviço Geológico dos Estados Unidos, UQAC - Universidade de Quebec em Chicoutimi, IPT - Instituto de Pesquisas Tecnológicas, ON - Observatório Nacional e COC - Universidades COC, desenvolveu estudo geológico e hidrogeológico de detalhe em área localizada no distrito de Bonfim Paulista, município de Ribeirão Preto (SP) (Figura 1), com o intuito de responder a seguinte questão: existe recarga do Sistema Aquífero Guarani (SAG) através dos basaltos do Aquífero Serra Geral (ASG)?

A motivação deste estudo é o fato do SAG, importante e estratégico manancial de água potável do Brasil, estar sendo ameaçado, em termos de qualidade e quantidade, devido à instalação de grandes centros urbanos em áreas constituídas de basalto e próximas ao afloramento do SAG. Concentrações elevadas de nitrato e cloreto, detectadas em poços do SAG, na área urbana de Ribeirão Preto, levaram a considerar a possibilidade desta contaminação chegar ao SAG através de fraturas transmissivas verticais do ASG. Assim, o projeto "A Formação Serra Geral como conexão hidráulica entre a superfície e o Sistema Aquífero Guarani: análise estrutural e ensaios in situ - FRATASG" realizou investigações geológicas e hidrogeológicas de detalhe para contribuir para o entendimento do fluxo vertical através dos basaltos.

Os métodos utilizados no projeto envolveram desde mapeamento geológico de detalhe e estudo das estruturas tectônicas rúpteis, até ensaios hidráulicos e estudos hidroquímicos e isotópicos. Neste artigo são apresentados os resultados referentes ao levantamento estrutural de detalhe no distrito de Bonfim Paulista, além de dados coletados em região maior no município de Ribeirão Preto e arredores. Um modelo hidrogeológico conceitual, construído com base em mapeamento de detalhe, apresentado em Fernandes et al. (2010), e nos resultados do levantamento estrutural é apresentado no final do trabalho.

\section{MÉTODOS}

O estudo estrutural da área de Ribeirão Preto envolveu: elaboração de mapa de lineamentos, levantamento sistemático de fraturas ao longo de scanlines e levantamento e análise de estruturas tectônicas. Os métodos envolvidos em cada uma destas abordagens são descritos abaixo.

\section{Elaboração de mapas de lineamentos}

Mapas de lineamentos foram elaborados sobre os seguintes materiais:

1. Modelos digitais de elevação do terreno segundo iluminações provenientes de N, E, N45E e N45W nas escalas 1:100.000 (SRTM - Shuttle Radar Topographic Mission, resolução de $90 \mathrm{~m}$ ) e 1:10.000 (cartas topográficas 1:10.000, do IGC, publicadas em 1992).

2. Fotos aéreas de 1965 da USAF, escala 1:60.000.

3. Fotos aéreas 1:25.000.

4. Cartas topográficas digitais, 1:10.000, do IGC.

A atividade de interpretação foi realizada de forma independente por dois técnicos e sobre os mesmos materiais, de modo a reduzir a subjetividade da interpretação. Após isto a dupla de intérpretes, em conjunto, realizou uma triagem dos lineamentos, chegando a um mapa único para a área de Bonfim Paulista.

\section{Levantamento de fraturas e análise estrutural}

Os levantamentos geológicos na área de estudo consistiram em descrição de 50 afloramentos que permitiram um reconhecimento da geologia de Ribeirão Preto e a elaboração de mapa geológico, compatível com a escala 1:25.000, para a área de Bonfim Paulista. Dados de fraturas tectônicas foram coletados na região como um todo, mas com mais detalhe na área de Bonfim Paulista. Nesta mesma área foi realizado levantamento sistemático de fraturas ao longo de scanlines e em poços construídos no projeto FRATASG, através da utilização de perfilagens acústicas pela ferramenta Borehole Acoustic Televiewer (BHTV). A seguir é feita uma descrição dos métodos empregados.

\section{Levantamento sistemático de fraturas ao longo de scanlines}

O levantamento sistemático de fraturas em afloramentos de boa qualidade (pedreiras e cortes de rodovias), pelo 

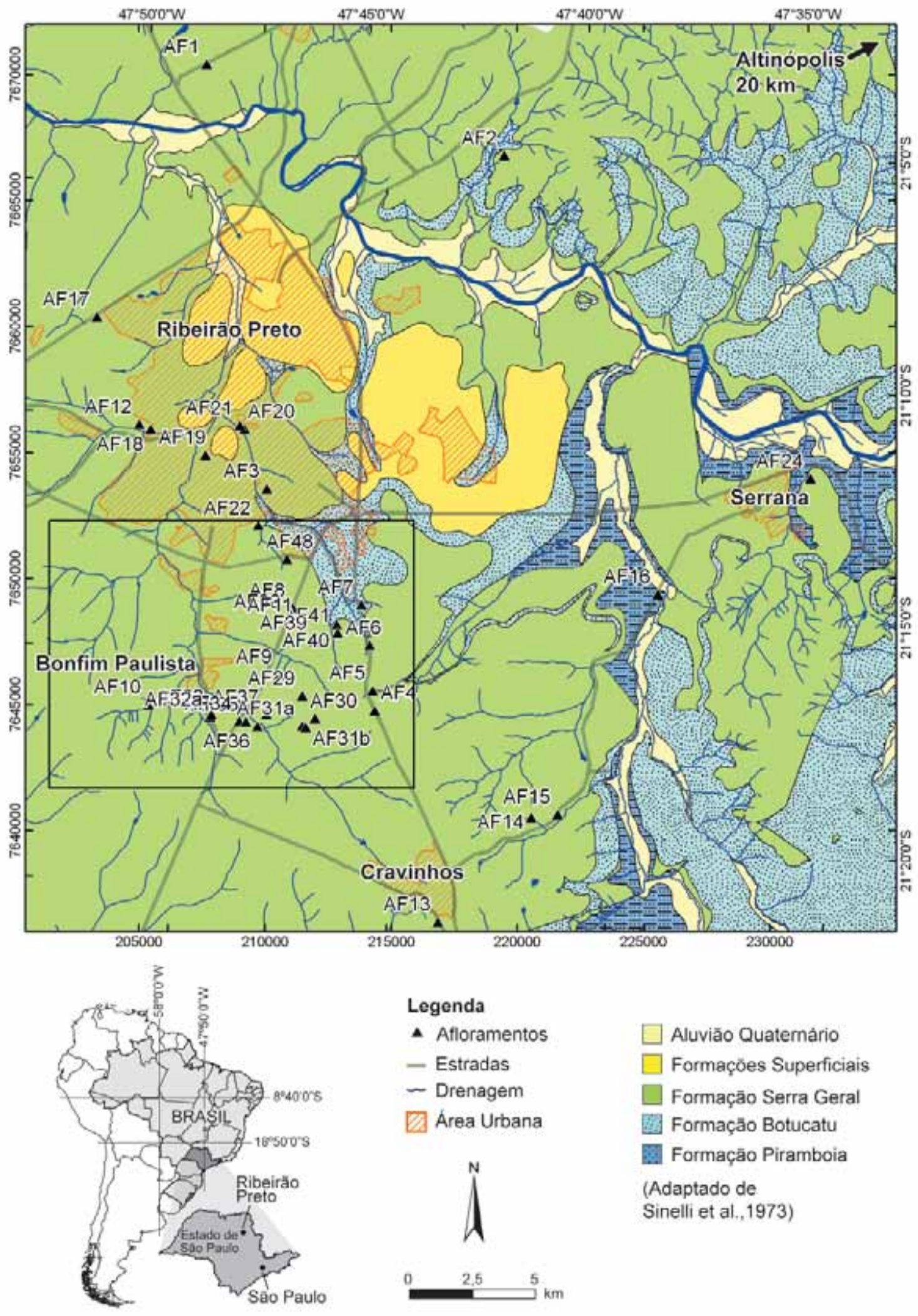

\section{Legenda}

- Afloramentos

- Estradas

- Drenagem

A Área Urbana

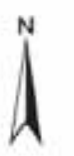

$\stackrel{2.5}{-5} \mathrm{~km}$

\section{$\square$ Aluviāo Quaternário}

$\square$ Formaçōes Superficiais

$\square$ Formaçāo Serra Geral

国 Formaçăo Botucatu

Formaçāo Piramboia

(Adaptado de

Sinelli et al.,1973)

Figura 1. Mapa geológico regional com localização da área de estudo e dos afloramentos descritos. 
método das scanlines, descrito em Rouleau e Gale (1981), consiste em descrever cada uma das fraturas que secciona uma linha de comprimento definido e teve como objetivo a melhor caracterização de parâmetros geométricos das fraturas, tais como espaçamento, comprimento, etc. Isto permitiu modelagem de rede de fraturas apresentada em Fernandes e Rouleau (2008). Em cada um dos afloramentos AF6, AF7, AF8, AF9, AF11 e AF22 (Figura 1), foram realizadas duas scanlines horizontais, na medida do possível em paredes de orientações distintas, de modo a evitar distorções causadas pela amostragem. Scanlines verticais também foram realizadas em alguns dos afloramentos com o objetivo de caracterizar as fraturas sub-horizontais. Os dados foram registrados em planilhas e, das informações coletadas, de forma individual para cada fratura, as mais importantes foram: atitude, espaçamento, feição genética (estrias indicando cisalhamento, ou "costelas" e "plumas", indicando geração por extensão), tipo de fratura, preenchimento/revestimento e terminações. Com isto foi possível identificar trends principais de fraturas e os espaçamentos característicos para cada grupo. As terminações, coletadas de forma sistemática, permitem identificar com que frequência os vários grupos de fraturas se propagam através de camadas menos competentes, como de basalto vesicular e amidaloidal (B-VA), que se localizam no contato entre os basaltos. Este dado foi de extrema importância para deduzir o grau de conexão hidráulica entre os derrames basálticos adjacentes. Principalmente nas pedreiras, pelo fato de serem afloramentos muito grandes e de poderem apresentar domínios estruturais distintos, foi avaliado se as scanlines realizadas eram representativas de tais domínios.

\section{Levantamento e análise de estruturas tectônicas}

Estudar a tectônica que atuou sobre basaltos defronta-se com a questão de distinguir fraturas formadas como resultado do resfriamento, que ocorrem em grande quantidade, daquelas formadas posteriormente, pela atuação de esforços tectônicos. As fraturas subverticais dos basaltos podem ser divididas em dois tipos: as que delimitam e as que não delimitam colunas. Quando as fraturas subverticais delimitam colunas, tendo em geral distribuição isotrópica, a gênese por resfriamento é inequívoca.

Por outro lado considera-se que a geração tectônica é indicada pelas seguintes feições:

1. Padrões de fraturas conjugadas.

2. Zonas de fraturas subparalelas e com trends bem definidos, por vezes anastomosadas, indicando que o cisalhamento foi o mecanismo de sua propagação, e distribuídas em faixas estreitas, em geral com largura de centímetros a decímetros (ver exemplos no item "Fraturas subverticais").
3. Fraturas de maior continuidade que se propagam dos níveis de basalto denso para os níveis B-VA, pois, de acordo com a zonalidade normal dos basaltos, as fraturas subverticais de resfriamento tendem a não cortar o B-VA.

4. Fraturas que se propagam em camadas de arenito intertrappe, por vezes bem desenvolvidas e com trend(s) direcional(is) bem definido(s).

A presença de planos de falha com estrias de atrito e degraus (steps) perpendiculares indica a atuação de esforços tectônicos, tanto em estruturas originalmente de resfriamento como as geradas por esforços tectônicos.

Nos casos 1 e 2, a origem tectônica é provável, mas, de acordo com Long e Wood (1986) fraturas de aspecto tectônico podem ocorrer em basaltos (principalmente de menor espessura), pois o deslocamento do derrame, durante o processo de resfriamento, ao longo do paleo-relevo, atua no sentido de criar esforços anisotrópicos. Já derrames mais espessos tenderiam a formar lagos de lava onde tais esforços não atuam. No entanto, considera-se aqui que conjugados ou zonas de fraturas claramente posteriores às fraturas de resfriamento devem ter origem tectônica. Exemplos disto são os conjugados (por vezes mais de um evento) cujas terminações são condicionadas por fraturas de resfriamento, ou ainda quando uma determinada superfície de fratura é constituída pela união de segmentos de juntas colunares (ver exemplos no item "Fraturas subverticais").

Preenchimento das fraturas por fases hidrotermais semelhantes ao preenchimento de vesículas e amídalas, também é comum. A idade do mesmo é difícil de identificar, pois podem se relacionar à fase hidrotermal do final do resfriamento ou a percolações posteriores quando os basaltos estavam em maiores profundidades.

O levantamento das estruturas tectônicas na presente pesquisa teve como objetivos a determinação: 1 . dos trends de fraturas tectônicas mais importantes e que podem servir como conexão hidráulica entre os vários derrames e destes com o Sistema Aquífero Guarani; 2. dos vários eventos tectônicos pós-basaltos e de sua superposição no tempo, sendo que, a princípio, o evento mais jovem determinaria a direção atual do fluxo principal de água subterrânea. Para isto, o levantamento consistiu em:

1. Medição da atitude das fraturas e das estrias de atrito, determinação do sentido de movimento e tratamento dos dados pelo método dos diedros retos (Angelier e Mechler, 1977).

2. Observação de relações angulares e medição de pares conjugados para determinação da posição do esforço máximo principal.

3. Anotação de relações de superposição entre estruturas. 
A determinação de eventos tectônicos é feita a partir da análise conjunta dos dados mencionados acima. A determinação do sentido de movimento pode ser feita com base em vários tipos de indicadores, descritos na literatura por Petit (1987) e Angelier (1994). Na área de estudo foram identificados 3 tipos: 1. degraus formados por minerais; 2 . degraus formados na rocha e relacionáveis aos conjugados de Riedel; 3. alternância de faces polidas e faces de cristalização de minerais. Estes foram classificados em positivos, quando o sentido de movimento é concordante com o mergulho do degrau que indica o movimento (tipo 1), e negativos, quando ocorre o contrário (tipo 2); o tipo 3 é uma composição de indicador negativo (faces polidas) e positivo (degraus de minerais).

As relações de superposição entre os vários eventos ou campos de esforços identificados basearam-se na interação entre grupos de fraturas atribuídas a eventos distintos. Fraturas mais jovens terminam em fraturas mais longas pré-existentes e, portanto, são mais curtas. Ou seja, no momento em que as fraturas mais curtas foram formadas, as mais longas já existiam e, por isso, controlaram a propagação das primeiras (Price e Cosgrove, 1990).

\section{TRABALHOS ANTERIORES}

Uma síntese da geologia da Formação Serra Geral é apresentada em Fernandes et al. (2010), cujo foco é a estratigrafia dos basaltos de Bonfim Paulista e da região de Ribeirão Preto, bem como da sua caracterização física e química.

Existe pouca informação disponível a respeito da geologia estrutural da Formação Serra Geral bem como uma análise da tectônica pós-basaltos. Os dados da literatura provem quase exclusivamente dos trabalhos sobre caracterização de fundações de barragens. Dentre estes, Bjornberg e Kutner (1983) elaboraram síntese das características estruturais das barragens em basalto no Estado de São Paulo, na qual descrevem fraturas subverticais tectônicas, no entanto o fluxo importante de água subterrânea está associado às, assim denominadas, juntas-falha sub-horizontais. Para a região sul brasileira (bacias dos rios Iguaçu e Uruguai), no entanto, Marques Filho et al. (1981) e Bjornberg e Kutner (1983) ressaltam o controle estrutural dos rios e a ocorrência de numerosos lineamentos, além de zonas de fraturas subverticais com estrias indicando movimentação transcorrente bem como falhas normais com rejeitos de alguns metros a dezenas de metros. Estas estruturas subverticais também constituem caminhos de fluxo de água subterrânea. Marques, Magalhães e Serra Júnior (1987) descrevem, na barragem de Porto Primavera, fraturas subverticais de direção N45-55W com estrias indicando movimentação transcorrente em basaltos e fraturas N84E com movimentação sinistral nos arenitos da Formação Caiuá.
Na região sul brasileira ocorrem numerosos lineamentos tectônicos e macro-fraturas com direções N60-70W, N60-70E, N10-40W e N10-40E, sendo muitas delas de fraturamento intenso subvertical, parte delas com estrias (que indicam predomínio de movimentos horizontais sobre os verticais) e presença de zona central brechada com preenchimento calcítico ou de argilas expansivas; os rios Iguaçu e Uruguai são controlados estritamente por lineamentos tectônicos (Marques Filho et al., 1981).

\section{GEOLOGIA DA REGIÃO DE BONFIM PAULISTA - RIBEIRÃO PRETO}

De acordo com Fernandes et al. (2010), na área de Bonfim Paulista ocorrem quatro derrames de basaltos denominados, do mais antigo para o mais jovem, de B1, B2, B3 e B4 (Figura 2). A ocorrência de B4 é muito restrita, pois foi erodido em grande parte. B1 e B2 apresentam espessuras de, em média, 45 e $55 \mathrm{~m}$, respectivamente. Os quatro basaltos são do tipo sheet-like-lobes e devem ter sido colocados por inflação, processo descrito em Self, Keszthelyi e Thordarson (1998). B1 apresenta espessa crosta vesicular superior e, assim como B2, pode apresentar mais de um nível vesicular no topo. Colunas de resfriamento foram observadas em B2 e B3, sendo mais conspícuas em B3, constituído por uma camada colunada inferior (B3-C) e outra justaposta com entablamento (B3-E). B3 é o mais espesso $(75$ a $100 \mathrm{~m})$ e contém brechas hidráulicas distribuídas em bolsões, posicionados na camada B3-C, ou ao longo de fraturas sub-horizontais, que hoje permitem circulação de água subterrânea. Descrição detalhada da geologia da região, principalmente da área de Bonfim Paulista é feita em Fernandes et al. (2010).

\section{ANÁLISE ESTRUTURAL}

A análise estrutural em basaltos deve considerar que, nestas rochas, estão presentes fraturas cuja gênese relaciona-se ao resfriamento e, a princípio, não têm relação com esforços tectônicos. As fraturas de resfriamento são controladas pelo paleo-relevo e pelo mecanismo de colocação do basalto, o qual controla as dimensões e formatos dos corpos. Fernandes et al. (2010) consideram que o mecanismo de colocação dos basaltos de Bonfim Paulista/Ribeirão Preto foi de inflação, no qual o derrame é alimentado por lava colocada sob crosta já solidificada de basalto, e que os derrames são do tipo sheet-like-lobes, ou seja, são corpos tabulares de grandes dimensões laterais. Esta crosta é rica em vesículas e sob ela ocorre basalto denso onde abundam as fraturas subverticais. A maioria destas tem sua propagação controlada pelo resfriamento que ocorre das bordas (inferior e superior) para o centro do derrame. As isotermas 

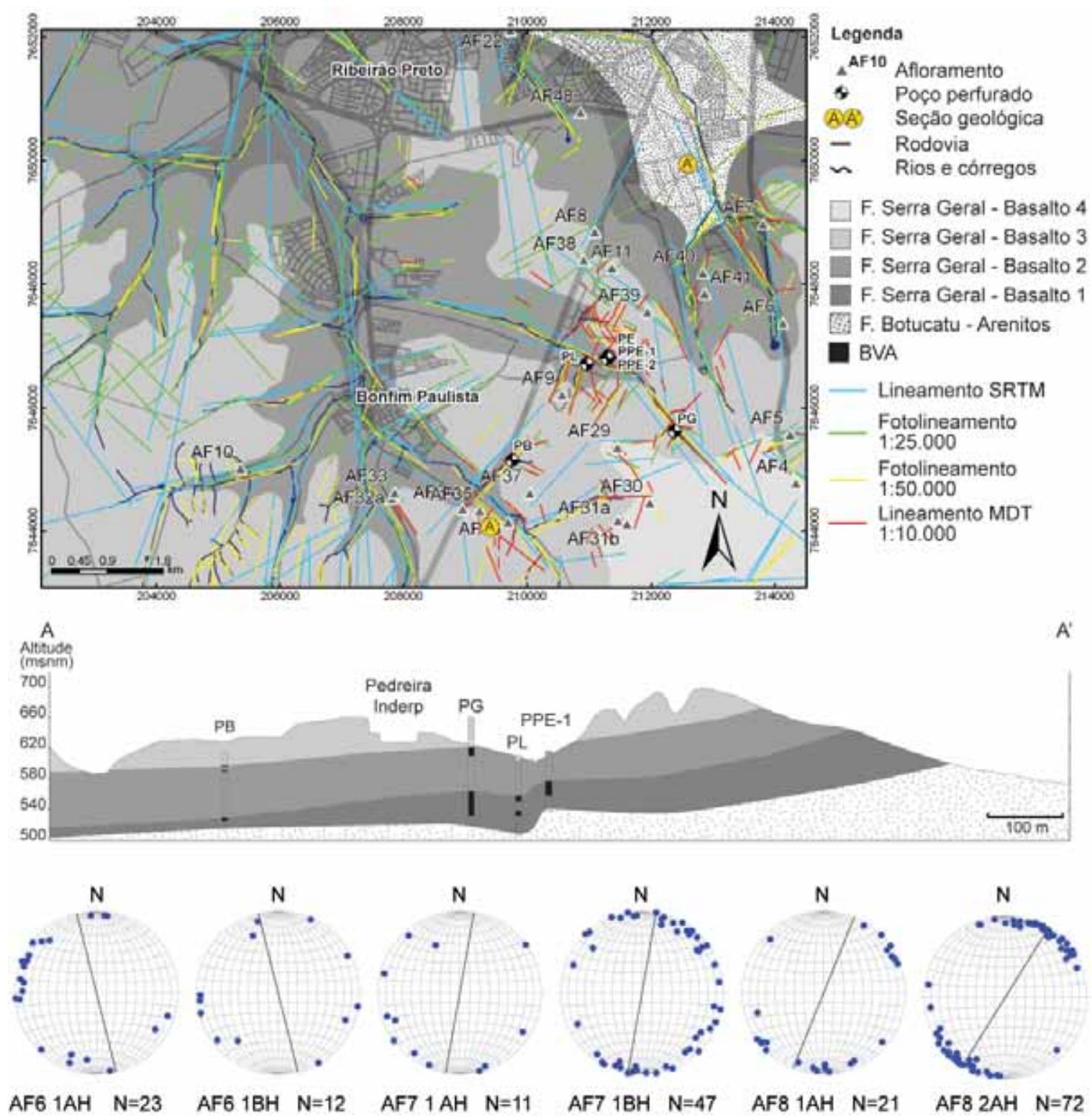

AF6 1AH $\mathrm{N}=23$ AF6 1BH N=12 AF7 1 AH N=11 AF7 1BH $\mathrm{N}=47$ AF8 1AH $\mathrm{N}=21 \quad$ AF8 2AH $\mathrm{N}=72$

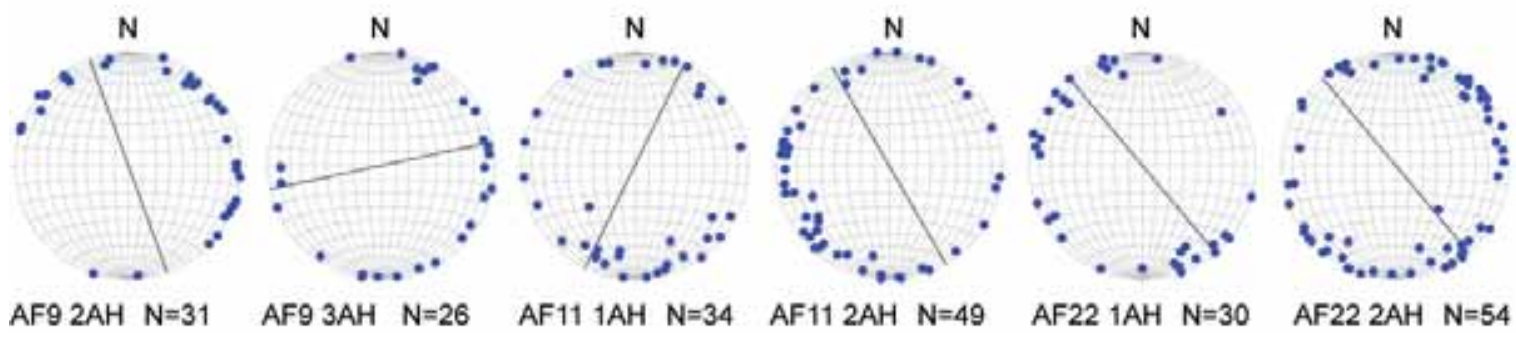

Figura 2. Mapa e seção geológica de Bonfim Paulista, modificados de Fernandes et al. (2010), e estereogramas das fraturas medidas ao longo de scanlines com identificação do afloramento (ex., AF6) seguida do nome da scanline (ex., 1AH) e do número de fraturas medidas (N). O traço reto no estereograma representa a direção da parede do afloramento onde foram realizadas as medidas. O s afloramentos das scanlines localizam-se no mapa. PB, PG, PL e PPE-1 são os poços perfurados e perfilados. SRTM: Shuttle Radar Topographic M ission; msnm: metros sobre o nível do mar; PB, PG, PL, PPE-1: poços perfurados no projeto FRATASG (ver texto). 
do derrame em resfriamento são, de um modo geral, paralelas a estes limites, os quais são próximos da horizontal. As fraturas propagam-se perpendicularmente às isotermas e, portanto, são de um modo geral verticais (Budkewitsch e Robin, 1994). Fraturas horizontais também são comuns e formam-se, muito provavelmente, devido à contração do derrame, durante o resfriamento. O alívio de pressão, que atua próximo à superfície em função da denudação, deve ser um fator relevante para o incremento da abertura das fraturas horizontais.

A seguir são descritas as fraturas horizontais e depois as subverticais. Com relação às últimas, procurou-se diferenciar as que delimitam colunas, inequivocamente relacionadas a resfriamento de lava, e as que não delimitam, bem como outras feições que indiquem origem relacionada a resfriamento ou a tectônica. Posteriormente, são apresentados os eventos tectônicos identificados na área de estudo a partir de uma síntese das estruturas verificadas em cada derrame. Uma vez que o objetivo do estudo é indicar os caminhos preferenciais de fluxo de água subterrânea nos basaltos de Ribeirão Preto, são apresentadas as feições indicativas da existência de fluxo.

\section{Fraturas horizontais}

Por praticidade, utiliza-se a expressão "fraturas horizontais", mas de fato são sub-horizontais ou, mais raramente, de mergulhos baixos. Sua extensão varia de decímetros a dezenas ou mesmo centenas de metros; no basalto denso, apresentam espaçamento decimétrico a métrico e podem ser preenchidas por sílica microcristalina e calcita. Os maiores comprimentos foram observados em B3-E e as mais conspícuas, e com fluxo de água importante, estão no AF11 tanto no contato entre B3-C e B3-E, em meio ao basalto denso, na profundidade de $40 \mathrm{~m}$, como no contato entre B2 e B3, na profundidade de 55 m (Figura 3). Ambas atingem extensão lateral mínima da ordem de centenas de metros e a ocorrência de cisalhamento é indicada pelo padrão lenticular e anastomosado das fraturas e pelas suas superfícies lisas, contendo estrias de atrito. No contato B2/B3, estas fraturas ocorrem imediatamente abaixo de camada contínua, de $20 \mathrm{~cm}$ de espessura, de brecha contida na base de B3 e constituída de fragmentos de B3-VA e matriz de calcita e quartzo com algumas cavidades (Figura 3C e 3D). No contato B3-C/B3-E também ocorre uma camada de brecha, menos espessa (centimétrica) e mais irregular, sendo constituída por fragmentos de basalto denso, afanítico, parcialmente alterado, marrom avermelhado, em matriz verde (clorofeíta, hidrobiotita) ou branca (quartzo microcristalino, calcita e zeólitas), por vezes amarronzada (argilomineral ferruginoso) (Fernandes et al., 2010). Imediatamente acima do contato B2/B3, e dentro de B3-C, também ocorrem bolsões de brecha, que contém fragmentos de B3-VA com vesículas achatadas e rotacionadas. Neste caso, os fragmentos de B3-VA estão contidos em basalto menos vesicular, ou seja, a crosta de basalto vesicular formada inicialmente foi englobada por lava do mesmo derrame (autobrecha), possibilitando a rotação dos fragmentos ainda em estado plástico. Este bolsão dispõe-se abaixo de $45 \mathrm{~m}$ de rocha fresca, no entanto apresenta-se muito alterado. A alteração que gerou o material terroso e amarronzado foi causada pelo fluxo de água subterrânea ao longo da fratura horizontal no contato B2/B3, com a qual o bolsão está conectado. A maior porosidade dada pelas vesículas, provavelmente conectadas por pequenas fraturas, deve ter sido um facilitador para o fluxo e alteração. Cristalização de calcita e alteração terrosa também está presente na camada descontínua de arenitos entre B2 e B3 (Fernandes et al., 2010). A hipótese aventada para a origem destas estruturas no contato B3-E/B3-C é a seguinte:

1. B3 foi colocado sobre uma superfície com paleo-relevo ondulado, o que ocasionou isotermas de resfriamento onduladas e, consequentemente, o "contato" também ondulado entre B3-E e B3-C, já que as fraturas que delimitam as colunas se formam paralelamente ao gradiente termal, que é perpendicular às isotermas (Budkewitsch e Robin, 1994).

2. B3-C esfriou muito mais lentamente que B3-E, permitindo a segregação de voláteis durante a cristalização do basalto, no entanto, estes voláteis não puderam ascender devido à rápida solidificação de B3-E. Assim, os voláteis migraram lateralmente de áreas de maior pressão para áreas de menor pressão, dentro do nível B3-C, acumulando-se em bolsões onde foi solidificado o basalto vesicular. É provável que as áreas de menor pressão correspondam a locais com menor espessura de B3-E sobre B3-C, e onde a espessura do derrame é menor. A topografia do contato B3-C/B3-E, no AF11, eleva-se no local de ocorrência de bolsão de brecha, sugerindo uma espessura menor de B3-E neste local. É importante notar que no AF9, onde o contato B3-C/B3-E foi observado por toda a pedreira, não foram observadas nem fraturas horizontais de grande extensão e nem bolsões de brecha. Este local é topograficamente mais baixo que o do AF11 e a espessura de B3-E é possivelmente maior, havendo, portanto, um peso maior de rochas acima do contato B3-C/B3-E. Os voláteis tenderiam a migrar desses locais para aqueles em que o peso de rochas sobrepostas é menor. Assim, o AF9 representaria um local onde a pressão de fluidos foi menor, não havendo a possibilidade de ocorrer fraturamento hidráulico.

3. Acúmulo adicional de fluidos, com a progressiva solidificação da lava, levou ao fraturamento hidráulico ao longo dos contatos B2/B3 e B3-C/B3-E, para onde, 

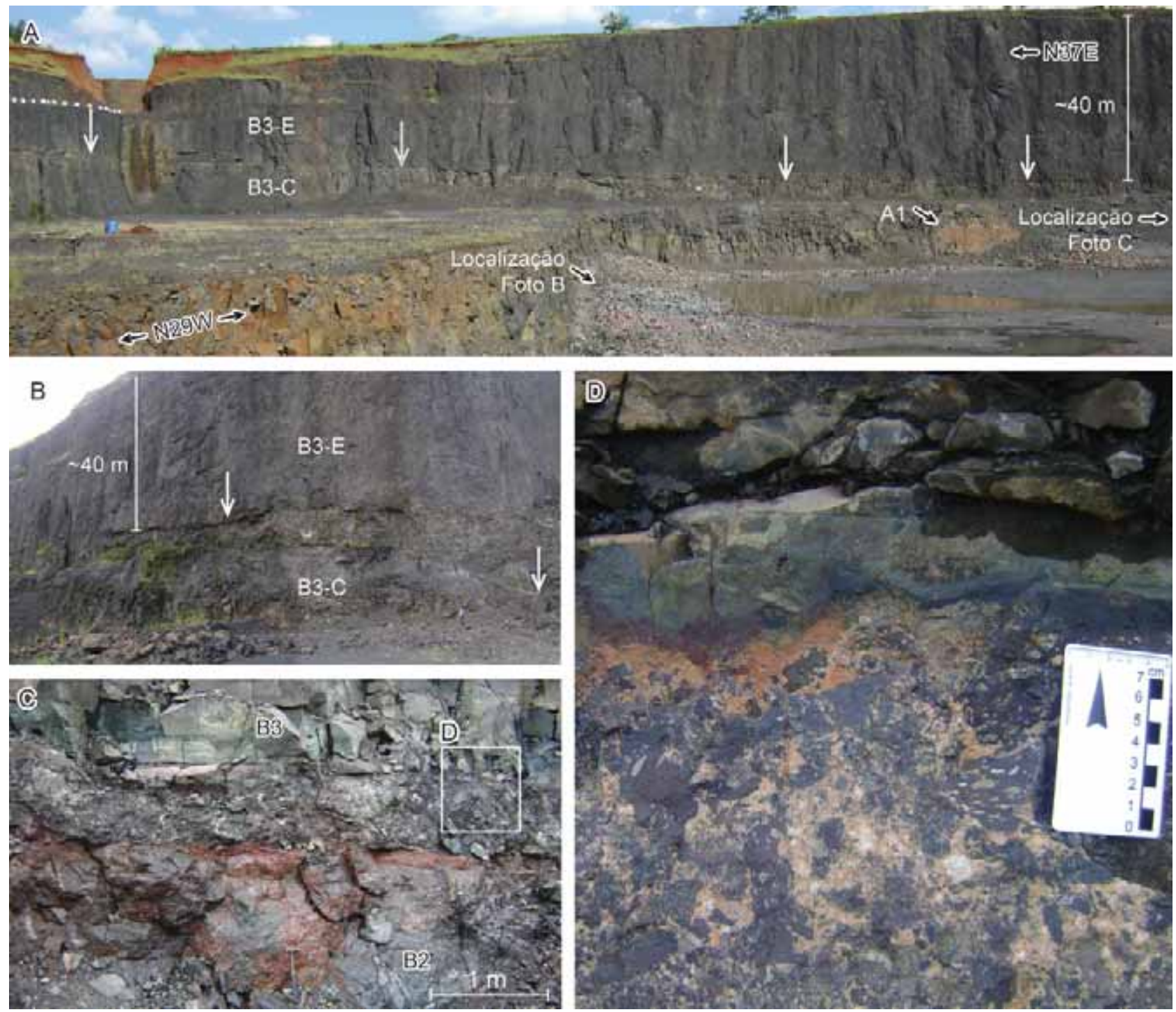

Figura 3. AF11. Fraturas horizontais com importância para o fluxo de água: (A) e (B) no contato B3-C e B3-E, em meio ao basalto denso, até a profundidade aproximada de $40 \mathrm{~m}$; e (C) no contato B2-B3, na profundidade aproximada de 55 m. (D) é detalhe de (C), mostrando a brecha que ocorre na base de B3. Notar em (A1) bolsão de basalto vesicular alterado abaixo de pacote espesso de basalto não alterado. Este bolsão conecta-se com a fratura horizontal mostrada na foto $C$, indicando fluxo de água importante ao longo da fratura. A extremidade esquerda da foto (A) corresponde ao local das fotos $(A)$ e (C) da Figura 6, onde ocorre alteração importante ao longo de fraturas verticais e horizontais. Notar que este tipo de alteração não ocorre no restante do paredão da foto (A). Em (B) observa-se que a fratura horizontal (acompanhada por vegetação - flecha da esquerda), no contato B3-C e B3-E, passa a ser fratura de baixo ângulo e entra em B3-C, ao mesmo tempo em que deixa de ser acompanhada por vegetação (flecha da direita).

subsequentemente migraram mais fluidos que, após se solidificarem, passaram a formar a matriz da brecha. O fato do fraturamento hidráulico gerar fraturas horizontais, que em parte aproveitaram superfícies pré-existentes (contatos B3-C e B3-E e B2/B3), indica que o esforço mínimo principal $(\sigma 3)$ era vertical e que, portanto, havia um esforço máximo compressivo $(\sigma 1)$, horizontal. O mergulho de algumas destas fraturas, ainda que bastante baixo, e a presença de líquidos percolantes, propiciou o cisalhamento ao longo das estruturas, mostrando se tratarem de fraturas híbridas, pois extensão e cisalhamento atuaram em conjunto. Na Figura 3B observa-se que a fratura 
horizontal é acompanhada por vegetação (flecha da esquerda), indicando maior fluxo e abertura (predomina extensão), no contato B3-C e B3-E. Esta fratura passa a ser de baixo ângulo e entra em B3-C, ao mesmo tempo em que deixa de ser acompanhada por vegetação (flecha da direita), ou seja o fluxo é menor, a fratura é mais fechada e observam-se feições de cisalhamento, como anostomosamento das fraturas.

No AF11, estas estruturas, no contato B3-C e B3-E, mergulham de NE para SW (Figura 3A), o qual coincide com o mergulho acentuado dos contatos entre os derrames na seção AA' (Figura 2).

No AF8 a superfície de contato entre B3-E e B3-C também é ondulada e marcada por um nível de espessura de $0,5 \mathrm{~m}$, que contém veios brancos (sílica microcristalina ou zeólitas), descontínuos e sub-horizontais, e muitas fraturas de baixo ângulo, em contraposição às juntas colunares subverticais de B3-E, imediatamente acima, e fraturas subverticais de $\mathrm{B} 3-\mathrm{C}$, imediatamente abaixo. Os veios horizontais e as fraturas de baixo ângulo indicam fraturamento hidráulico (atuação de elevada pressão de fluidos causada pelo acúmulo e confinamento de voláteis neste local) com esforço tectônico mínimo vertical e máximo horizontal. Bjornberg e Kutner (1983) consideram que o desconfinamento lateral junto aos vales seria uma das causas do cisalhamento que ocorre ao longo das grandes fraturas sub-horizontais em basaltos (denominadas pelos autores de juntas-falha). No entanto, na presente área de interesse, tais fraturas são concomitantes à percolação de líquidos hidrotermais, indicada pela matriz das brechas associadas às fraturas. As temperaturas associadas a este processo são incompatíveis com as profundidades rasas requeridas pelo mecanismo de desconfinamento lateral junto a vales de um relevo semelhante ao atual.

Assim, as fraturas horizontais de grande extensão, são talvez as feições mais importantes para o fluxo de água subterrânea para a área de estudo, como indicado pelas saídas de água verificadas em afloramentos (Figura 3), já anteriormente apontadas por Fernandes et al. (2006).

\section{Fraturas subverticais}

Dados estruturais de fraturas foram levantados em afloramentos e ao longo de perfilagens acústicas (BHTV) em cinco poços, permitindo visualização e elaboração de estereogramas das fraturas que cortam os basaltos em profundidade. Os poços construídos são cortados por fraturas cujos mergulhos são bastante variáveis, conforme mostrado na Figura 4, predominando, no entanto, as de alto ângulo de mergulho. Nenhuma fratura subvertical foi registrada pelo BHTV nos intervalos constituídos por B-VA. Nos afloramentos também foi verificado que, em geral, os níveis de B-VA apresentam poucas e descontínuas fraturas (Figuras $5 \mathrm{D}$ a $5 \mathrm{~F}$ ), tanto subverticais como horizontais, apesar de algumas das horizontais observadas serem muito extensas, como descrito acima. Uma vez que as fraturas subverticais de resfriamento não se propagam nos B-VAs, supõe-se que as estruturas planares e constituídas por várias fraturas subparalelas presentes naqueles níveis sejam de origem tectônica. Assim, conclui-se que nenhum dos poços intercepta estrutura subvertical tectônica de maior importância.

A densidade real para as fraturas do mesmo grupo (mesmo trend direcional), calculada pelo método dos cossenos, empregado em Fernandes e Rouleau (2008), de uma dada scanline, mostra que as densidades das fraturas subverticais variam de 0,04 a 4 fraturas $/ \mathrm{m}$; todas as distorções, causadas pelo fato das scanlines serem subparalelas ou próximas às direções das fraturas, foram eliminadas da análise. A densidade média é 0,7 fratura $/ \mathrm{m}$ e a mediana é 0,5 fratura $/ \mathrm{m}$. Os valores de $25 \%$ e de $75 \%$, das distribuições acumuladas, correspondem a 0,4 e 0,9 fratura/m, respectivamente.

A seguir são descritas as fraturas subverticais observadas em cada um dos derrames mapeados, no afloramento da Formação Botucatu mais próximo da região de estudo, localizado em Altinópolis (SP), e em dois corpos de arenitos intertrappe. Após isto serão descritos os eventos tectônicos que afetam os basaltos de Ribeirão Preto.

\section{Basalto 1}

O Basalto 1 (B1) foi observado no AF7, AF24 e nos 5 poços perfurados (Figuras 3 e 5). B1 não apresenta colunas de resfriamento, sendo que as fraturas presentes tendem a ser contínuas, na escala dos afloramentos, e planas ou onduladas. Parte destas fraturas de superfície planar corta também o nível B1-VA e algumas, cuja direção varia de NNW a ENE, com predomínio das que estão no quadrante NE, encontram-se preenchidas por mineral acicular fibrorradiado de cor cinza-creme (provavelmente zeólita), ou ainda minerais brancos (sílica microcristalina) e quartzo em cristais pontiagudos, semelhante ao dos geodos. $\mathrm{O}$ quartzo indica fase hidrotermal inicial; a zeólita é posterior e forma-se a partir de fluidos de temperaturas intermediárias $\left(<200^{\circ} \mathrm{C}\right)$ (Frank et al., 2008). Tal hidrotermalismo pode ter ocorrido durante o resfriamento dos basaltos, tanto do derrame que seccionam como de um posterior. Michelin et al. (2008) propõem que parte do preenchimento de fraturas e vesículas aconteceu em época posterior, por percolação de líquidos presentes em areias saturadas, sotopostas aos derrames, que teriam sido injetadas nos basaltos devido à ocorrência de tremores.

Parte das fraturas subverticais que seccionam os níveis vesiculares e a porção densa de B1 apresentam estrias 


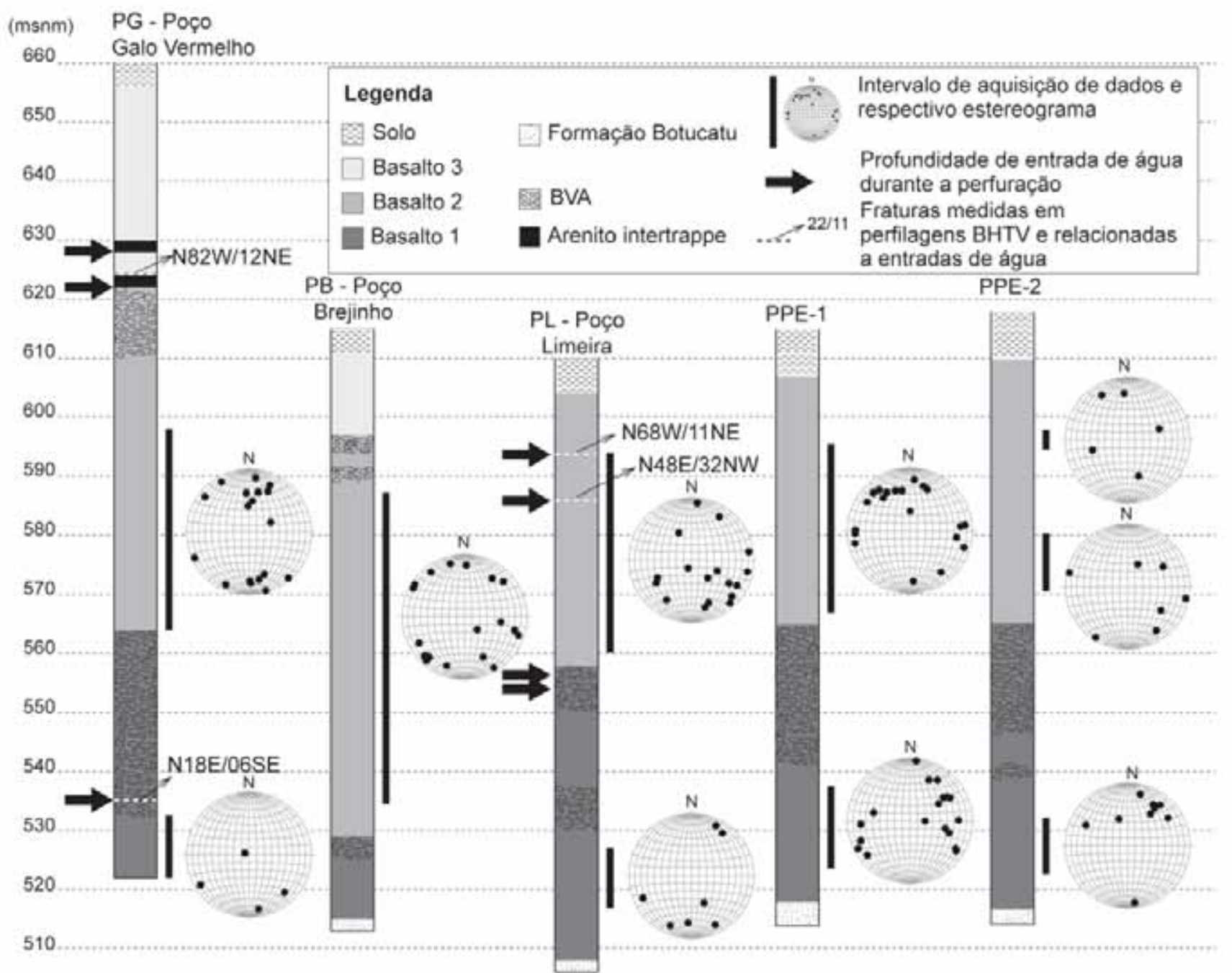

Figura 4. Perfis litológicos dos poços perfurados no projeto FRATASG. Perfilagens acústicas (BHTV - Borehole Televiewer) permitiram a identificação e medição de fraturas (representadas nos estereogramas). As entradas de água em 54 e 56 m, no PL , foram deduzidas a partir das perfilagens de temperatura e de condutividade elétrica descritas em Wahnfried (2010) e as demais foram detectadas durante a perfuração dos poços. BVA: basalto vesicular e/ou amidaloidal.

acompanhadas por pequenos degraus na rocha (steps, ver item "Levantamento e análise de estruturas tectônicas"), mostrando atividade tectônica que gerou ou reativou tais fraturas. Estas estruturas são apresentadas no item "Eventos tectônicos".

A densidade de fraturas, de acordo com as duas scanlines realizadas no AF7, situa-se predominantemente entre 0,1 e 0,6 fratura/m (Fernandes e Rouleau, 2008), sendo que o valor mais elevado (acima da mediana, quando todas as scanlines são consideradas) corresponde a grupo de fraturas com direção em torno de N50W, coerente com as direções dos lineamentos mais conspícuos próximos ao AF7. A Figura 4 mostra estereogramas das fraturas que cortam
B1 nos poços PG, PL, PPE1 e PPE2. Não foram observadas fraturas em $\mathrm{B} 1$, no poço $\mathrm{PB}$.

No AF24, próximo ao município de Serrana (SP), além de não terem sido observadas colunas em B1, parte das fraturas presentes são bastante contínuas na vertical (pelo menos $20 \mathrm{~m}$ ) e constituem zonas de fraturas subparalelas geradas por cisalhamento (de provável origem tectônica), de espessura centimétrica, com predomínio das direções N60-80E e N60-75W, que cortam também a porção vesicular de B1 (Figura 5D). A porção vesicular também é cortada por fraturas planas e contínuas de direções N30-80E (predominante) e N65W (subordinada). Fraturas de direção N10$-35 \mathrm{E}$ e EW, também estão presentes. 

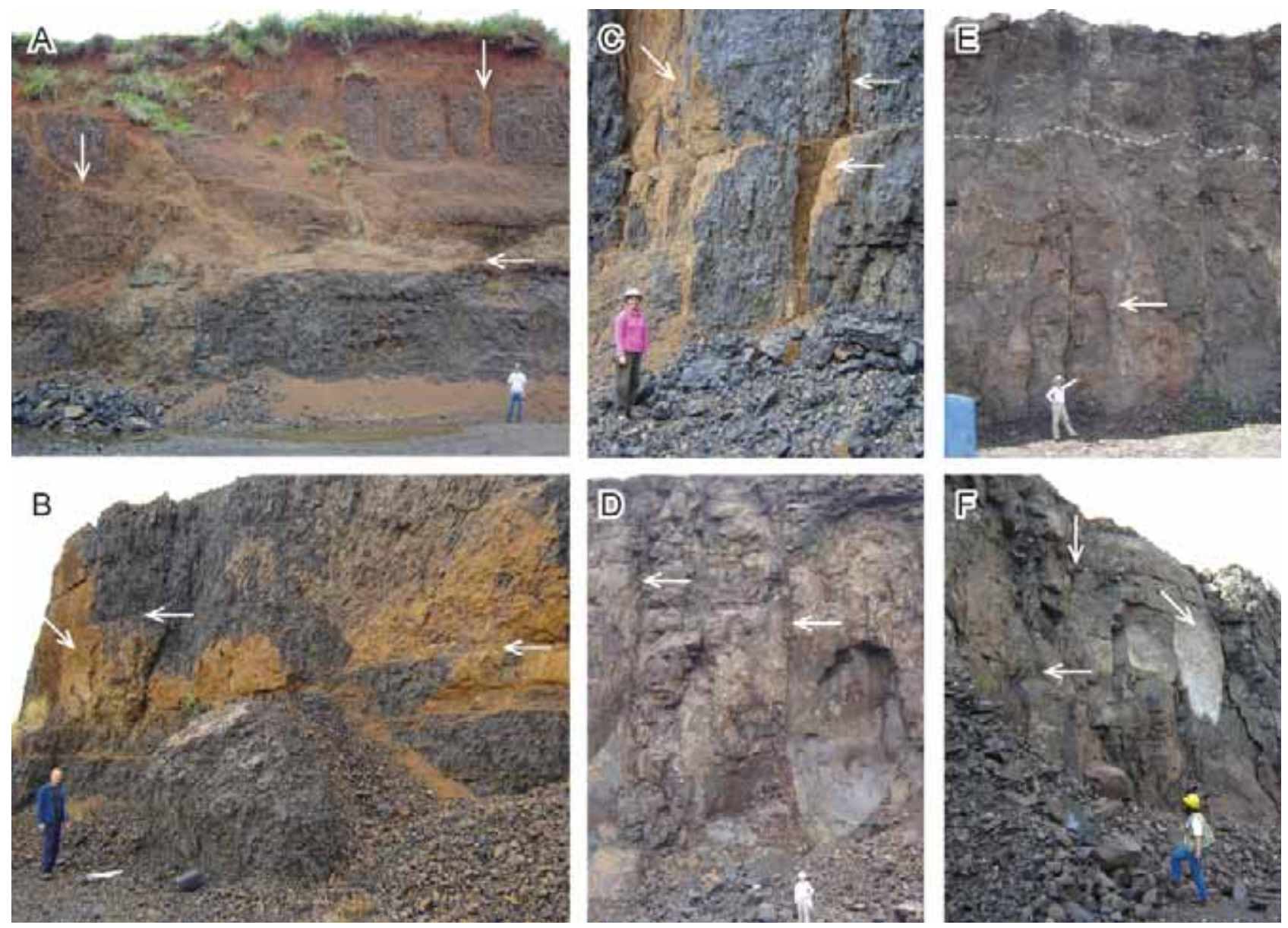

Figura 5. A., B., C. e D. Fraturas horizontais próximas à superfície do terreno, de comprimento métrico ou de algumas dezenas de metros e acompanhadas por alteração intempérica pronunciada. E. e F. basalto vesicular de topo com poucas fraturas.

(A) AF11. N ota-se a interrupção das fraturas verticais quando estas atingem determinadas fraturas horizontais e a passagem gradativa de fraturas verticais a horizontais.

(B) AF9. Fraturas verticais (paredes ocre) que deixam de ocorrer abaixo de certas fraturas horizontais.

(C) AF11. Fraturas verticais mudam de posição ao passar pelas horizontais.

(D) AF24. Fraturas verticais de direção N60E seccionando B1 denso e vesicular presente no topo da parede.

(E) AF24. Basalto vesicular, na base, e peperito, no topo (contato entre ambos é marcado por linha pontilhada) sem fraturas significativas. A flecha indica a presença de dique de arenito. Peperito: material que se formou pela interação entre magma juvenil e sedimento, com ou sem a presença de água (Jerram e Stollhofen, 2002).

(F) AF24. Fraturas verticais e planares (faces esbranquiçadas) seccionando basalto vesicular.

\section{Basalto 2}

Estruturas do Basalto 2 (B2) foram observadas no AF6, 15, 22, 42 e 43. B2, em algumas porções, apresenta colunas de seção decimétrica e, em outras, apresenta fraturas não formadoras de colunas, por vezes com padrão tectônico.

No AF22 observam-se: porções com fraturas que não delimitam colunas e que são relativamente descontínuas e sem padrão definido; e porções com fraturas formando quatro gerações de pares conjugados relativas aos quatro eventos tectônicos identificados na área de estudo (descritos abaixo). As fraturas subverticais ocorrem na metade inferior do AF22; na metade superior dominam fraturas horizontais de extensão métrica e espaçamento métrico a decimétrico; as subverticais apresentam terminações superiores nas horizontais ou em curvas na rocha, evidenciando que as primeiras são mais jovens que as segundas. 
A densidade de fraturas, para o AF6, está predominantemente entre 0,1 e 0,4 fratura/m, com um valor anômalo de 1,3 fratura/m para a direção média N25E e valor elevado para a direção NS, encontrando correspondência com o importante trend NS de lineamentos (Figura 2). A densidade das fraturas, para o AF22, está predominantemente entre 0,2 e 1,7 fratura/m, sendo que os grupos de fraturas em torno de N75W, N10E e N40E apresentam densidades acima da mediana, e os grupos em torno de N70E, N45W apresentam densidades acima do valor de $75 \%$ para a distribuição acumulada; os lineamentos mais importantes, nas vizinhanças do AF22, apresentam direção N30-40W (Figura 2).

Preenchimento (ou revestimento) de fraturas foi observado em vários afloramentos (AF6, AF15, AF22), sendo mais conspícuo no AF15. É comum a presença de duas películas de mistura de celadonita e sílica microcristalina (em contato com a rocha) separadas entre si por uma película branca de sílica microcristalina e zeólita; também há fraturas-veio preenchidas por cristais grandes de calcita, provavelmente relacionados à circulação de água meteórica, como indicado por Frank et al. (2008) para derrame no Rio Grande do Sul.

\section{Basalto 3}

Com relação às fraturas que delimitam colunas, B3 é caracterizado, de acordo com Fernandes et al. (2010) por duas porções distintas:

1. Uma inferior, com espessuras estimadas de 15 a $20 \mathrm{~m}$, onde as colunas apresentam seção basal decimétrica (os lados das colunas medem desde $10 \mathrm{~cm}$ a até $75 \mathrm{~cm}$ e o diâmetro varia de 50 a $160 \mathrm{~cm}$ ). É compatível com o que é descrito na literatura como colunada, sendo denominada de B3-C.

2. Uma superior e bem mais espessa (pelo menos 60 $\mathrm{m})$, onde as colunas são mais finas. É compatível com o que é descrito na literatura como entablamento, sendo denominada de B3-E. B3-E apresenta colunas de primeira e segunda ordem, com lados de cerca de 15 a $30 \mathrm{~cm}$ e de 5 a $10 \mathrm{~cm}$, respectivamente.

Fernandes et al. (2010) sugerem que B3 tenha se solidificado em um período de tempo da ordem de 2 anos. O cálculo leva em conta o diâmetro das colunas, como proposto por Budkewitsch e Robin (1994), cujo modelo de resfriamento inclui a existência de correntes de convecção de fluidos nos espaços formados pelas fraturas.

Em B3-C e B3-E, o preenchimento mais comum, das fraturas que delimitam colunas, é o de duas películas de mistura de celadonita e sílica microcristalina (em contato com a rocha) separadas entre si por uma película branca de sílica microcristalina e zeólita. Vênulas brancas de espessura submilimétrica selam os espaços entre as colunas de segunda ordem de B3-E, junto às quais o basalto apresenta halos mais escuros de $0,5 \mathrm{~cm}$ de largura. Algumas scanlines foram realizadas na porção colunada (B3-C) nos AF9 e AF11, ao longo das quais foram medidas fraturas onduladas ou curvilíneas e de menor continuidade, que não formam concentrações ou assimetrias. No AF9 observou-se que estas fraturas delimitam colunas; no AF11 a dimensão lateral das fraturas é maior e não se observam colunas, no entanto, a ausência de trends direcionais predominantes, corrobora sua origem por resfriamento.

Fraturas que não delimitam colunas em B3-C foram observadas com clareza no AF8 tanto na forma de padrões conjugados como de predomínio nítido de determinadas direções com densidades muito elevadas, em que o espaçamento chega a ser centimétrico. Este é o caso de grupo de fraturas no intervalo N45-70W, com densidade de 4 fraturas/m, na scanline AF8-2AH (Figura 2) e, secundariamente, N30-45W e N70-80W, com densidades 1,7 e 1,14 fratura/m (todas acima do valor de $75 \%$ da distribuição acumulada), respectivamente. No B3-C do AF8, uma grande quantidade de fraturas de direção NE apresenta revestimento por sílica microcristalina impregnada por hidróxidos de ferro, onde se observa calcedônia fibrosa crescendo perpendicularmente às lâminas da sílica; na amostra de mão o revestimento é preto e de aspecto vítreo e em lâmina é marrom (Figura 6). Por outro lado, somente algumas poucas fraturas NW mostram este tipo de revestimento, indicando que a direção NE sofreu mais extensão durante a época de colocação do preenchimento. A sílica microcristalina que reveste as fraturas NE algumas vezes apresenta feições semelhantes às da zona periférica de fraturas extensionais (fringe ou shoulder zone, - Price e Cosgrove, 1990 ) indicando que tais fraturas foram novamente retomadas pelo modo I (Figura 6).

A existência de zonas de fraturas, muitas vezes constituídas da união de segmentos das fraturas que delimitam as colunas finas de B3-E (Figura 7), é uma evidência da retomada destas por esforços tectônicos. Tais zonas de fraturas, como observado no AF8, AF11, AF14 e AF41 são de espessura centimétrica a alguns decímetros, e constituem-se por várias fraturas subparalelas e anastomosadas (indicação de cisalhamento), com espaçamento milimétrico a centimétrico entre si. Estas zonas de fraturas apresentam-se fortemente alteradas a argilominerais ocre, são de grande continuidade, apresentam trends preferenciais, e suas superfícies são muito rugosas pelo fato de se constituírem da união de segmentos das fraturas que delimitam as colunas finas de B3-E. A Figura 7 apresenta exemplo destas fraturas medidas no AF8, AF14 e AF41. O trend direcional comum a todos estes é NNW (NS a N45W); no AF14, em ordem decrescente de importância, ocorrem os intervalos N50-60E, 

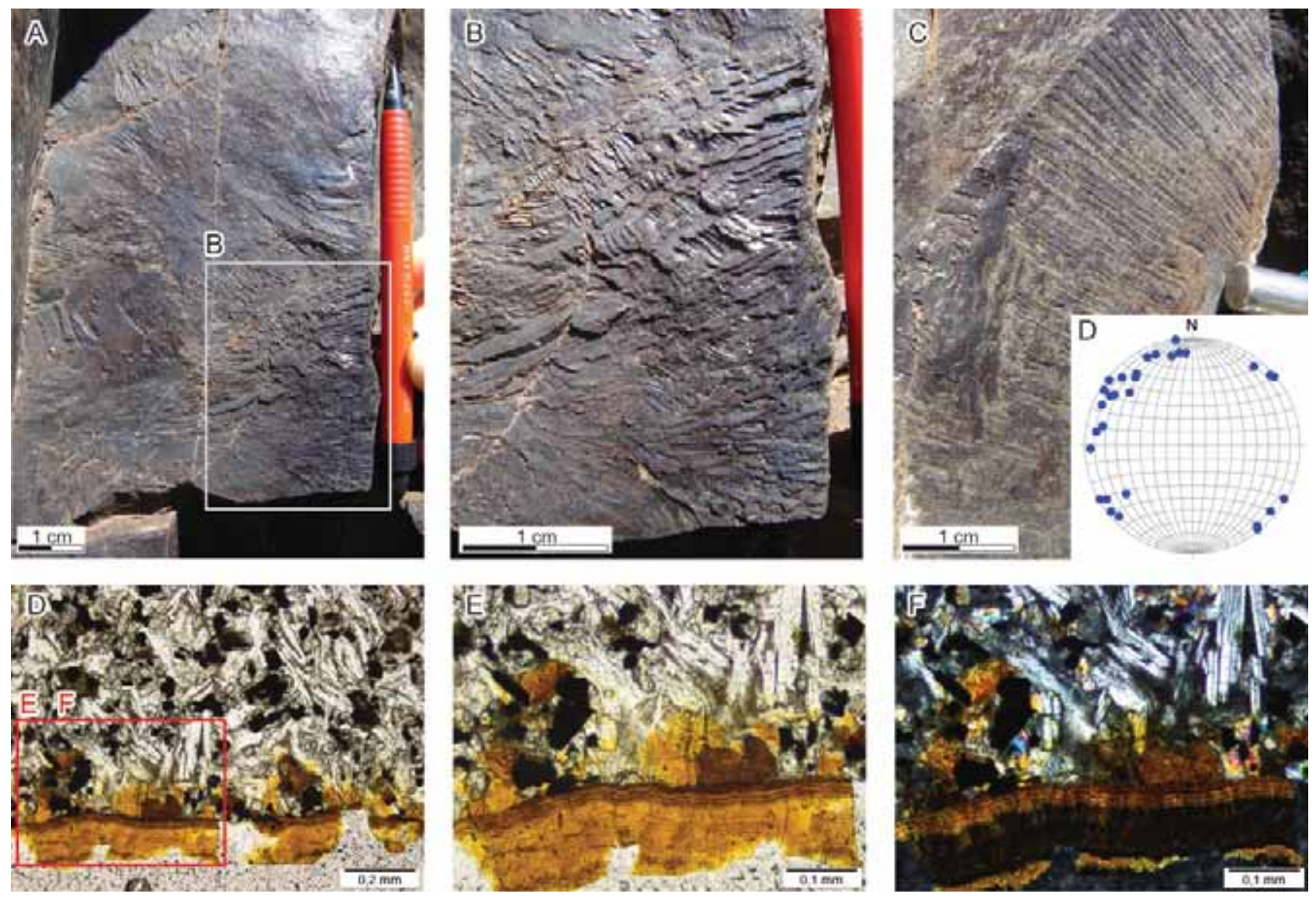

Figura 6. B3-C do AF8. Fraturas com preenchimento por sílica microcristalina preta que exibe feições de fraturas extensionais. A. Fratura de direção N50E. B. Detalhe de (A). C. Fratura de direção N24E. D. Uma quantidade muito maior de fraturas de direção NE, quando comparadas às de direção NW, como observado no estereograma, apresentam esse tipo de revestimento. E, F e G. Seção delgada mostrando o preenchimento da fratura. A cor marrom é devida à impregnação por hidróxidos de Ferro que foi mais intensa no contato rocha/revestimento. Com os nícois cruzados (G) observam-se lâminas marrons grosseiramente paralelas às fraturas e calcedônia (cinza escuro) que cresceu perpendicularmente às mesmas.

e N20-45W; no AF8 a direção EW também é importante. No AF41 (Figura 7C), a direção N45W é subparalela a encosta retilínea e a lineamentos de direção N40W, muito provavelmente controlada por estruturas tectônicas. As fraturas medidas neste afloramento, se projetadas no sentido N40W, vão passar muito próximo ao AF8, onde a direção NW é muito importante (Figura 2).

\section{Basalto 4}

AF4 é o único afloramento de B4 em que foram medidas fraturas (apenas 7); estas se distribuem em dois intervalos: 5 em N35-74W e duas em N30-50E. Devido à escassez de dados não é possível concluir sobre sua origem e direções predominantes.

\section{Arenitos}

Arenitos intertrappe ou da Formação Botucatu por vezes são seccionados por estruturas tectônicas. Isto foi observado no AF23, AF28 e AF33. Afloramentos da Formação Botucatu não existem em Ribeirão Preto ou seus arredores. Os mais próximos situam-se nos arredores da cidade de Altinópolis, onde foi descrito o AF23 (Gruta Itambé), e ocorrem sob a forma de escarpas e cavernas na região. As fraturas presentes no AF23 têm direções predominantes próximas a EW e NS. No fundo da caverna foi observada uma fratura contínua de direção $\mathrm{N} 80 \mathrm{E}$, e próxima à direção do seu alongamento, aproximadamente segundo N70W. Considera-se que é possível que a caverna tenha se desenvolvido nesta direção devido à presença de fraturas 
extensionais ao redor de EW, que condicionariam o fluxo principal de água no presente.

No AF28, próximo ao município de Araraquara (SP), e AF33, próximo a Bonfim Paulista, foram observadas estruturas tectônicas em arenitos intertrappe, que, no caso do AF33, estão no contato entre B2 e B3. Neste ocorrem fraturas subverticais no intervalo N10-55E, com predomínio da direção N30E (Figura 8A e B); o padrão indica a presença de fraturas conjugadas (com $\mathrm{R}_{1}$ ao redor de N50E, e $\mathrm{R}_{2}, \mathrm{~N} 10 \mathrm{E}$ ) $\mathrm{e}$, na sua bissetriz, fraturas extensionais $\mathrm{T}$ (direção ao redor de N30E), coerentes com o evento eNNE, descrito abaixo.

No AF28, fraturas N20E, N80E e no intervalo N65$-80 \mathrm{~W}$ cortam apenas a porção mais endurecida do arenito e do basalto sobreposto (Figura 8C). Esta porção mais endurecida é avermelhada e corresponde ao nível onde houve depósito de hidróxidos de ferro que coincide com o contato
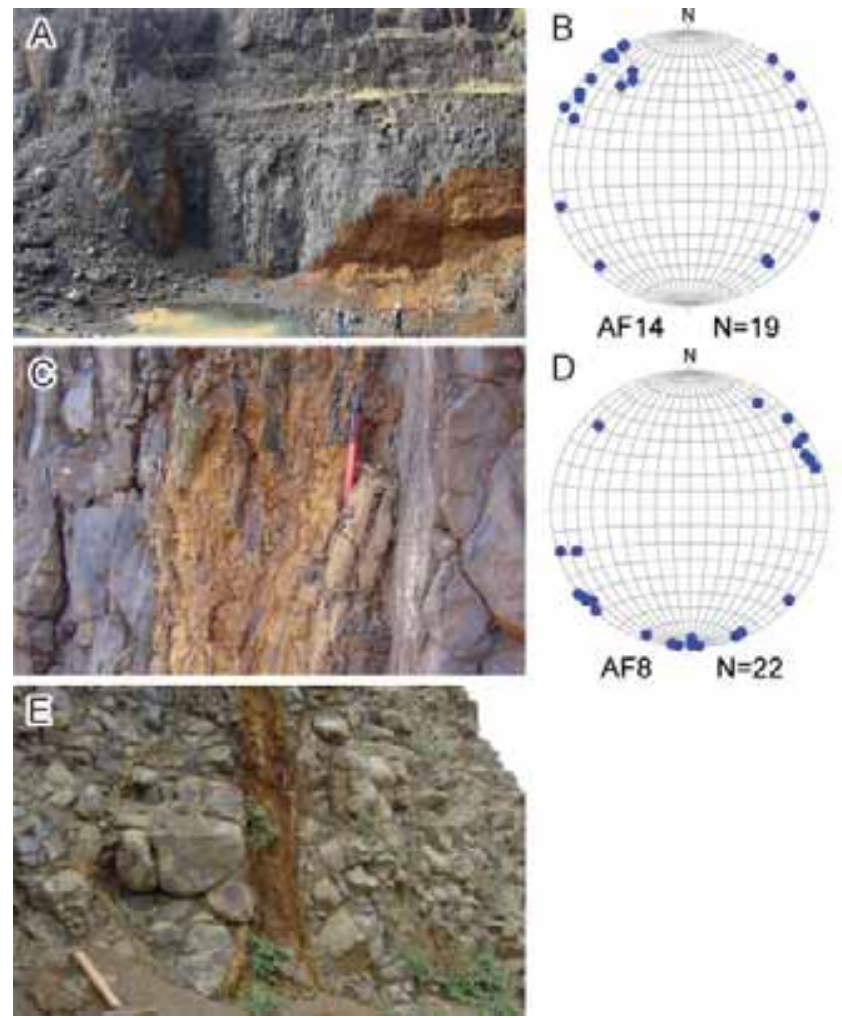

Figura 7. Fraturas tectônicas de alto ângulo, exibindo alteração ocre pronunciada e seccionando B3-C. (A) Zonas de fraturas no AF14, de grande continuidade, e (B) seu respectivo estereograma; as mais contínuas e frequentes são de direção ao redor de N50E e as menos contínuas, N40W; (C) zonas de fraturas no AF8 e (D) estereograma representando todas as zonas de fraturas alteradas medidas em B3-E no AF8; (E) zona de fratura de direção N50W no AF41. entre as rochas e o local de fluxo preferencial de água subterrânea no passado.

\section{Eventos tectônicos pós-basaltos}

Com base nas fraturas conjugadas e nos planos de falha estriados, foi realizada a investigação do posicionamento das direções de esforços associadas à geração e reativação de pequenas falhas transcorrentes, pós-basaltos, tendo sido identificados quatro direções principais para o esforço máximo principal $(\sigma 1)$ : N75E, N55W, NS e N30E (Figura 9). A direção N30W para $\sigma 1$ foi identificada apenas no AF22 e, devido a esta ocorrência restrita, considera-se mais adequado atribuí-la a uma variação local do evento com $\sigma 1$ de direção N55W. Aquelas direções principais de $\sigma 1$ podem ser correlacionadas aos eventos tectônicos transcorrentes, identificados no município de Campinas (SP) (Fernandes e Amaral, 2002; Fernandes e Melo, 2004), indo do evento mais antigo para o mais jovem, da seguinte forma: (1) a direção N75E pode ser correlacionada aos eventos mais antigos denominados por aqueles autores de eNE (anterior ao Neógeno) ou eEW (Neógeno); (2) a direção N55W, ao evento eNW; (3) a direção NS, ao evento eNS; (4) e a direção N30E ao evento eNNE. Segundo os autores, os eventos eNW, eNS e eNNE, são quaternários. Correlação parcial pode ser feita com outros autores para outras regiões do Estado (Riccomini, 1997; Salvador e Riccomini, 1995; Hiruma, Riccomini, Modenesi-Gauttieri, 2001) onde também foram identificados os eventos eNE e eNW (Fernandes e Melo, 2004). Riccomini (1997) descreve eventos, na região da Bacia Bauru, afetando a Formação Itaqueri na porção centro-leste do Estado de São Paulo, com $\sigma 1$ orientado segundo as direções EW, mais antigo, que teria atuado do Cretáceo Superior até parte do Neógeno, e NS, atuante durante o Quaternário. $\mathrm{Na}$ área de estudo, as interações entre fraturas (ver final do item "Levantamento e análise de estruturas tectônicas") sugerem que o esforço $\sigma 1$ N75E é mais antigo que os esforços ao redor de N55W, e este mais antigo que o NS e N30E. Este ordenamento cronológico é concordante com Fernandes e Amaral (2002) e Fernandes e Melo (2004) e, de modo parcial, também com Riccomini (1997).

A cronologia de eventos indica que houve uma rotação de $\sigma 1$ (talvez relativamente contínua e progressiva), no sentido horário, já sugerida por Fernandes e Amaral (2002) e Fernandes e Melo (2004). A orientação de SHmax atual, identificado para o sul do Cráton do São Francisco é ENE (Assumpção, 1998). Este SHmax provavelmente ainda não gerou registro geológico, mas implicaria na continuação da rotação horária com relação ao evento eNNE.

Os eventos identificados, denominados, a exemplo de Fernandes e Melo (2004), de eENE, eNW eNS e eNNE (Figura 9), são todos transcorrentes (falhas subverticais com 

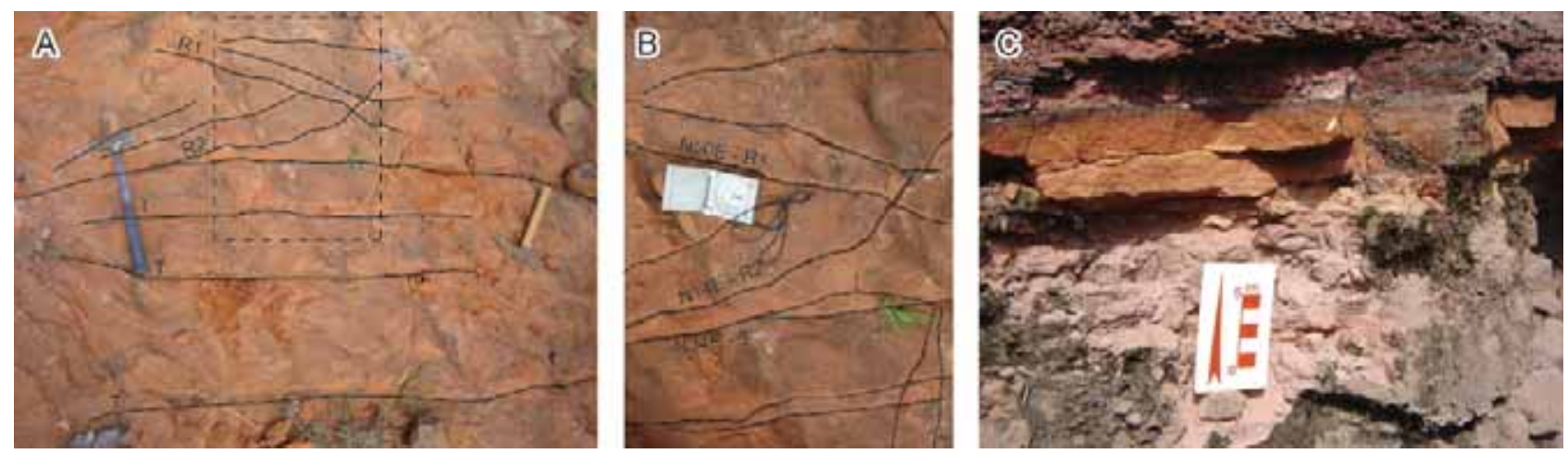

Figura 8. A. No AF33, arenitos intertrappe que ocorrem no contato B2/B3 são cortados por fraturas subverticais com R1 ao redor de N50E, R2, N10E e T, N30E. B. Detalhe de (A). C. No AF28, estruturas tectônicas em arenitos intertrappe: fraturas N20E, N78E e no intervalo N66-83W cortam a porção mais endurecida do arenito e do basalto sobreposto.

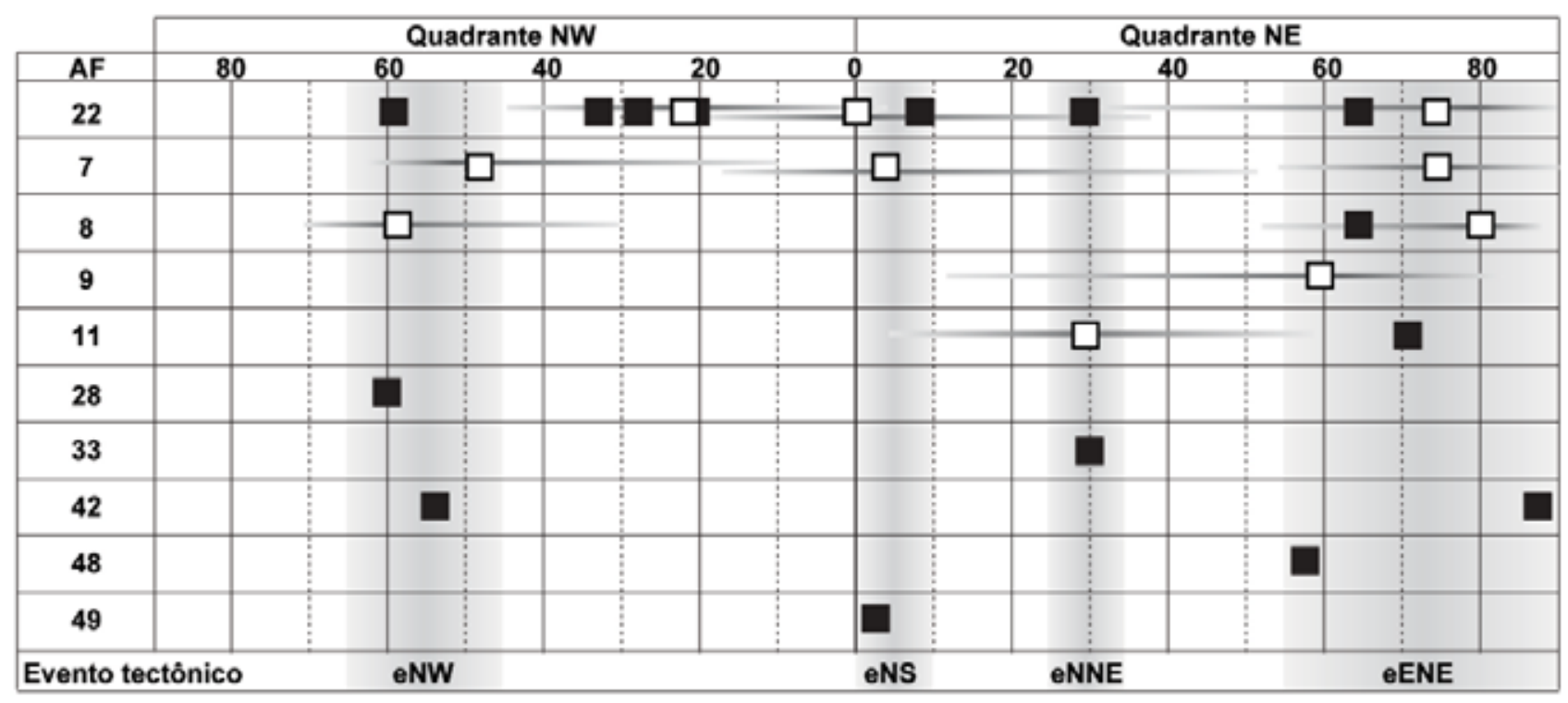

Figura 9. Sombreados correspondem aos intervalos de direções onde se encontra a orientação do esforço máximo principal $\sigma 1$ para cada um dos vários eventos tectônicos de acordo com o observado nos afloramentos. $Q$ uadrados cheios: orientação de $\sigma 1$ determinado com base em pares de fraturas conjugadas. Q uadrados vasados: maior probabilidade de corresponder à orientação de $\sigma 1$ determinado com base no método dos diedros retos (ver item "Métodos"); as barras correspondem às orientações cada vez menos prováveis de $\sigma 1$ à medida que se distanciam dos quadrados.

estrias sub-horizontais ou de caimento baixo). Para as bacias dos rios Iguaçu e Uruguai, Marques Filho et al. (1981) descrevem, em basaltos, o predomínio de falhas transcorrentes, que são mais frequentes que as normais, estas com rejeitos de dezenas de metros; os rejeitos das falhas transcorrentes são da ordem de 2 a 3 m. Isto mostra a atuação de uma tectônica pós-basaltos mais intensa do que na presente área de estudo. Tectônica transcorrente de idade cenozoica é amplamente descrita na literatura para a região sudeste do país.

$\mathrm{Na}$ área de estudo, o evento mais conspícuo é o eENE (Figura 10), identificado em 8 afloramentos, tendo sido observadas 66 fraturas (conjugadas ou com estrias e degraus) a ele relacionadas. Com relação ao evento eNW (Figura 11), foram medidas 66 fraturas em 6 afloramentos, e aos 

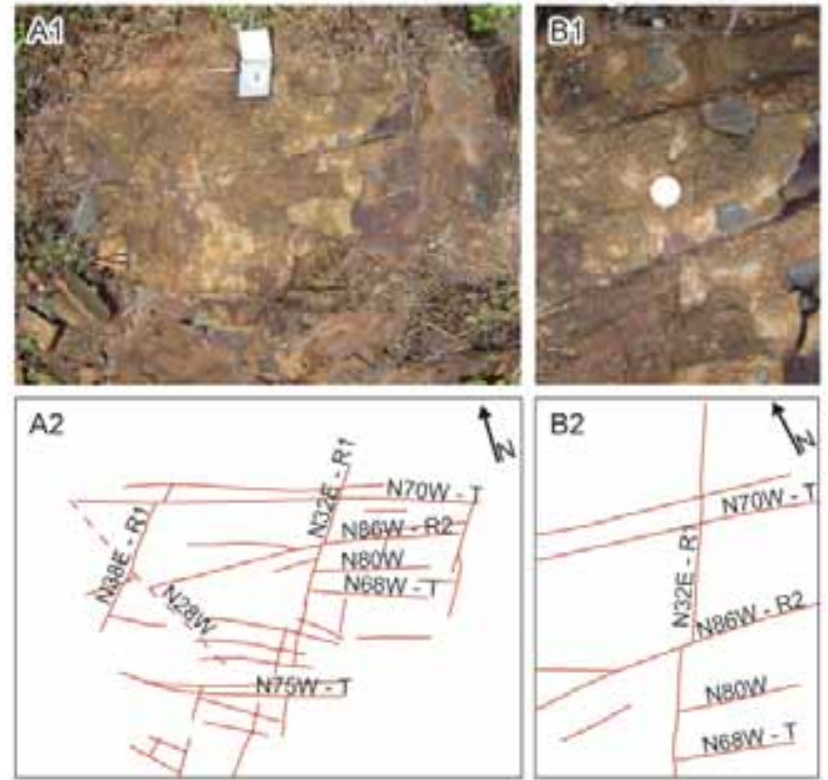

Figura 10. A1. e A2. AF8 visto em planta. Fraturas conjugadas R1 e R2, do evento eENE, correspondem às direções N 85-70W e N 35E, respectivamente. Isto indica a atuação de evento tectônico com $\sigma 1$ de direção ao redor de N65E. O AF8, destaca-se pela grande densidade de fraturas NW (ver SL-2AH na Figura 3) relacionáveis ao evento eENE (intervalo N 45-70W)e provavelmente eN S (intervalo N30-45W). A fratura N28W (tracejada) é anterior aos conjugados. B1. e B2. Detalhe de A. eventos eNS e eNNE (Figura 12), 29 e 31 fraturas, respectivamente, todas observadas em quatro afloramentos. A orientação de $\sigma 1$ para os vários eventos em afloramentos distintos pode ser visualizada na Figura 9. As Figuras 11 a 13 apresentam fotos e esquemas de estruturas relacionadas aos eventos. Os ângulos $2 \theta$ menores que $60^{\circ}$, para os conjugados do evento eENE, sugerem se tratar de fraturas híbridas, resultantes da atuação conjunta dos mecanismos de extensão e de cisalhamento (Dunne e Hancock, 1994) e a presença de fraturas extensionais (AF11 e AF48), rugosas e paralelas à bissetriz de $2 \theta$, indicam que o evento eENE foi trans-extensional.

A presença de fraturas veio, constituindo conjugados, além de fraturas bastante rugosas próximas da bissetriz de $2 \theta$, interpretadas como fraturas extensionais, mostra que o evento eNW também é do tipo trans-extensional (Figura 11).

A existência de cinco gerações de conjugados no AF22, indica que pelo menos as quatro mais novas sejam de origem tectônica, supondo que a geração mais antiga pode ter se formado devido à atuação de esforços anisotrópicos gerados pelo deslocamento do derrame, ao longo do paleo-relevo, durante o processo de resfriamento, descrito por Long e Wood (1986).

\section{Origem dos esforços que geram fraturas pós-resfriamento nos basaltos}

Os basaltos são sotopostos por arenitos da Formação Botucatu que, como atestado pelos poços perfurados, são pobremente consolidados. Em vista disso, pode-se colocar a seguinte questão: tais arenitos teriam a capacidade
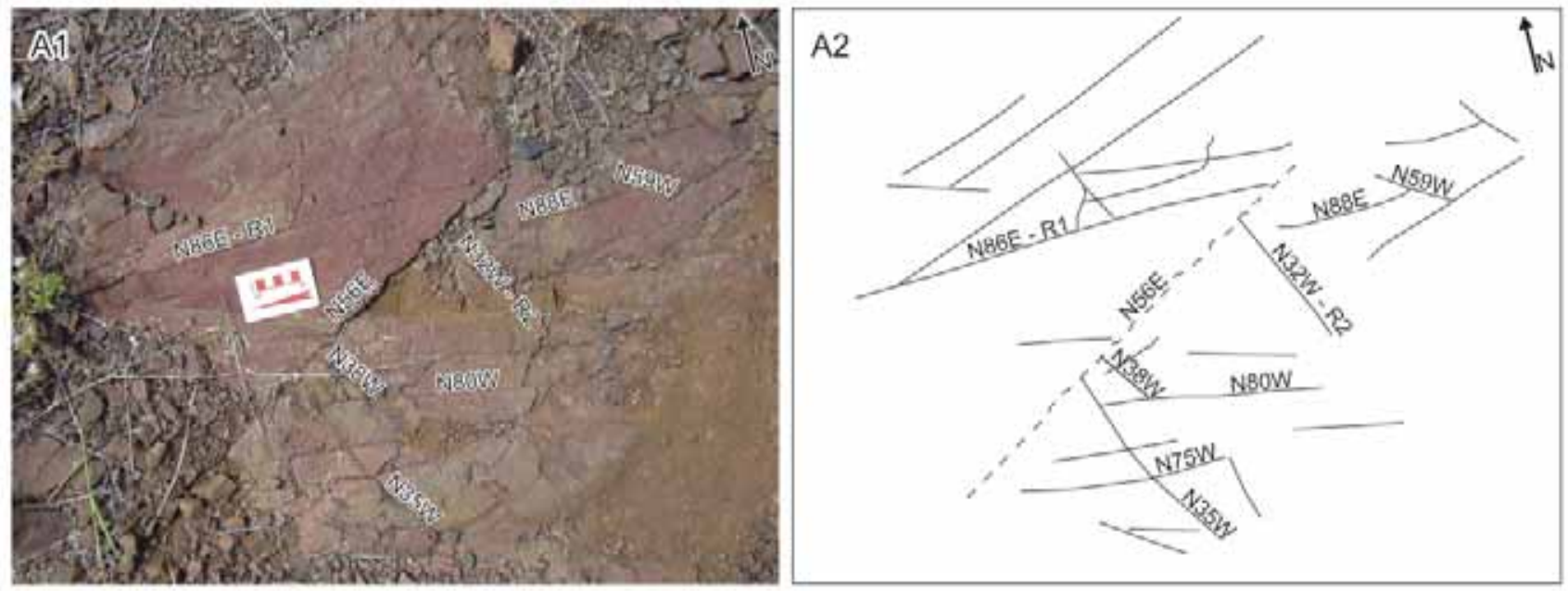

Figura 11. AF28 visto em planta. Fraturas subverticais conjugadas do evento eNW onde R1 está ao redor de EW e R2, ao redor de N35W. Notar que a fratura N56E (tracejada) é anterior aos conjugados. 

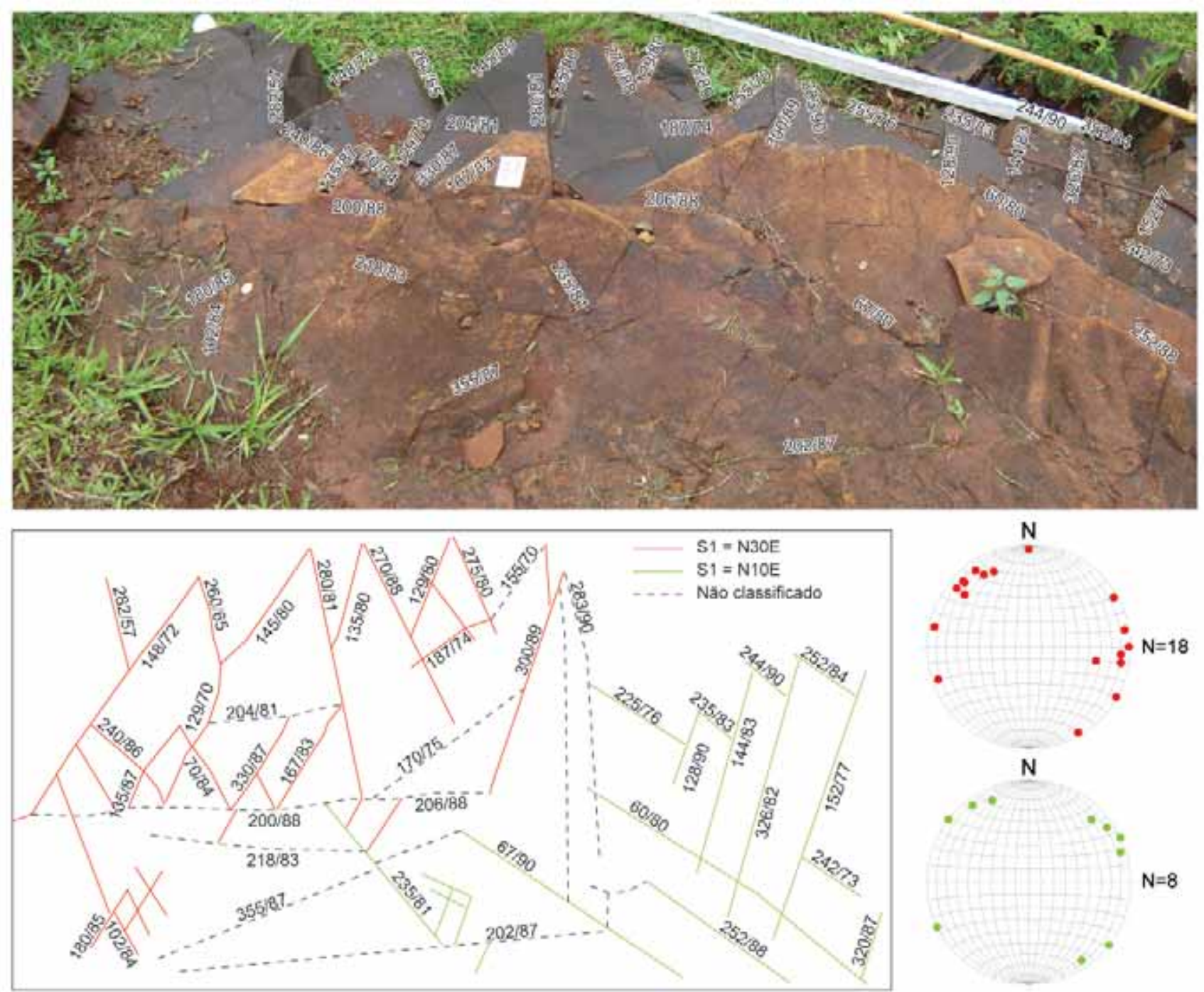

Figura 12. AF22. Evento eN S e eN NE cujas fraturas conjugadas e estereogramas são representados pelas cores verde e vermelho, respectivamente. As linhas tracejadas não são atribuíveis a nenhum dos dois eventos. Aqui é utilizada a notação da bússola Clar (dip direction), pois a notação em quadrante, como no restante das figuras e do texto, sobrecarregaria a figura.

de transmitir esforços tectônicos para a camada superposta de basaltos?

Uma explicação possível para a origem de esforços que fraturam rochas de bacias sedimentares com pouca deformação é descrita por Price e Cosgrove (1990). Sinteticamente, tais esforços associam-se à geração de um sinforme muito aberto devido à subsidência causada pelo peso das próprias rochas vulcânicas, ou seja, as condições de deformação seriam atectônicas. Assim, o esforço máximo principal $\sigma 1$ é vertical, e, devido à curvatura da Terra, os esforços principais $\sigma 2$ e $\sigma 3$ são compressivos e paralelos aos eixos menor e maior da bacia. Com isto seriam gerados dois grupos de fraturas ortogonais que podem corresponder a falhas normais ou a fraturas extensionais subverticais, ambas hidráulicas (geradas devido à atuação de pressão de fluidos) e dependentes das propriedades elásticas de cada tipo de rocha.

Esta hipótese não parece provável para a área de estudo porque o padrão de fraturas não é do tipo ortogonal. Além disso, falhas normais, às quais se associa $\sigma 1$ vertical, são raras na área. Predominam, como exposto acima, fraturas de várias gerações ou idades, conjugadas e subverticais, típicas de eventos transcorrentes, aos quais se associa $\sigma 1$ 


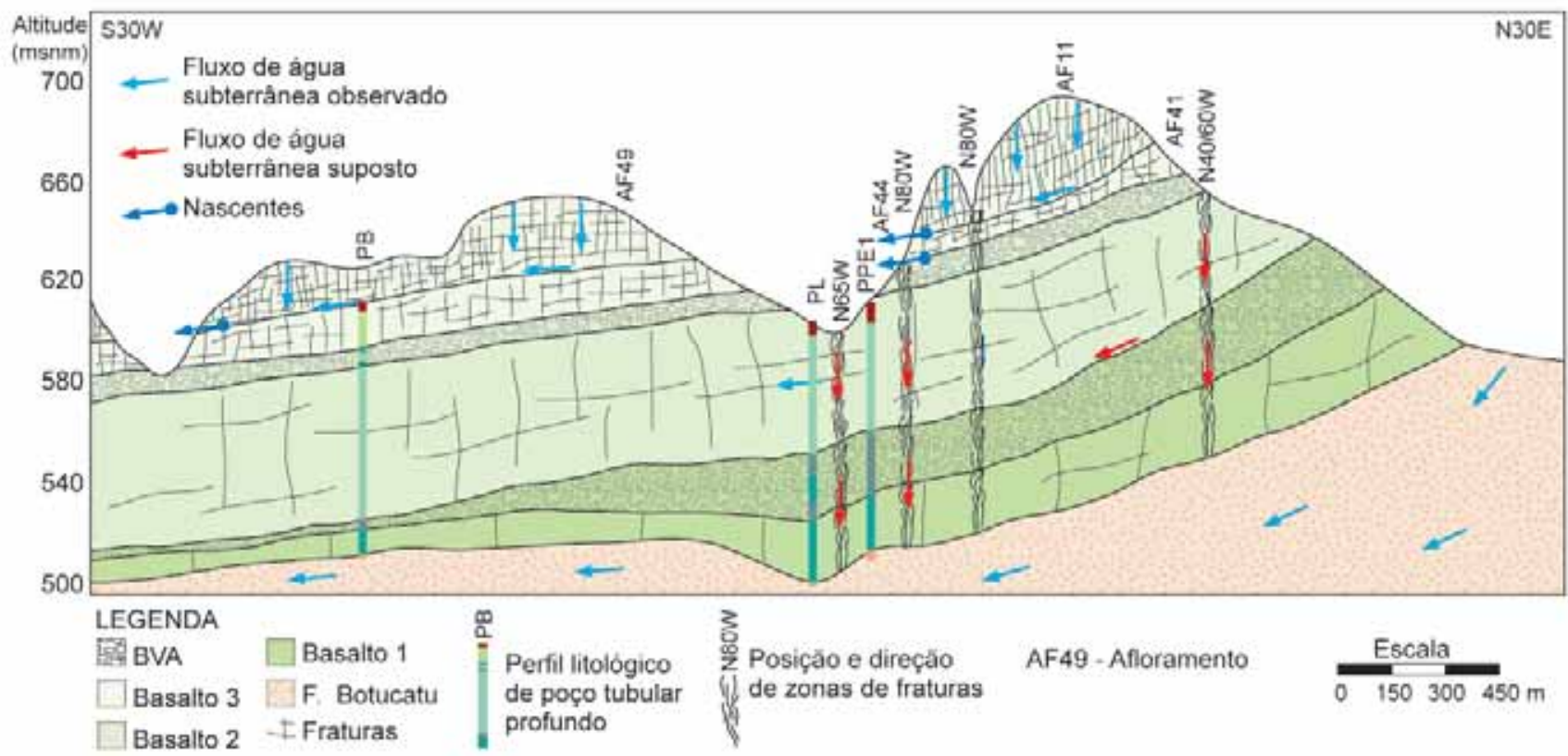

Figura 13. Modelo Conceitual. A zona de cisalhamento, ou zona de fraturas, de direção N 40-60W foi medida no campo e coincide com lineamento de mesma direção; as demais foram deduzidas apenas com base em lineamentos. BVA: basalto vesicular e/ou amidaloidal; msnm: metros sobre o nível do mar; PB, PG, PL, PPE-1: poços perfurados no projeto FRATASG (ver texto).

horizontal. Assim, esforços tectônicos propagam-se para os basaltos, apesar destes serem sotopostos por arenitos pouco consolidados. Uma hipótese viável é que isto seja possível devido à presença de diques de diabásio, que ligariam mecanicamente o embasamento da Bacia do Paraná aos basaltos, ou ainda à ocorrência de basaltos diretamente sobre o embasamento, isto ocorrendo em locais atualmente já erodidos.

\section{MODELO CONCEITUAL DE FLUXO DE ÁGUA SUBTERRÂNEA NOS BASALTOS DE BONFIM PAULISTA}

O mapeamento dos basaltos e identificação da sua estratigrafia em Bonfim Paulista, apresentados em Fernandes et al. (2010), bem como a descrição detalhada de estruturas e determinação dos eventos tectônicos, para a mesma área, apresentados neste trabalho, permitem apontar quais são os prováveis caminhos preferenciais de fluxo e servem de base para a elaboração do modelo conceitual de circulação de água subterrânea dos basaltos. A seguir serão descritas as estruturas ou feições que controlam o fluxo de água subterrânea próximo à superfície do terreno e quais têm o potencial de controlar fluxos verticais mais profundos, conectando o SAG com a superfície, através dos basaltos.
Como indicado por feições de alteração, a infiltração e o fluxo verticais ao longo de fraturas que delimitam colunas estendem-se até $15 \mathrm{~m}$ de profundidade. Em B3-E, possivelmente por conter grande quantidade de fraturas de resfriamento que permitem infiltração, fraturas sub-horizontais são acompanhadas por alteração intempérica pronunciada nos primeiros $15 \mathrm{~m}$ (AF11) a partir da superfície do terreno. Estas interceptam fraturas subverticais muito alteradas que estão conectadas com a superfície. A alteração das subverticais diminui abruptamente, de cima para baixo, após interceptar determinadas horizontais, indicando que o fluxo de água que se deslocava para baixo, ao longo das subverticais, passa a ocorrer predominantemente ao longo daquelas fraturas horizontais (Figuras 5A a 5C). Nos derrames B1 e B2 e em B3-C também são observadas fraturas horizontais nos primeiros metros junto à superfície, no entanto, a alteração não é tão pronunciada e os comprimentos são menores. Isto sugere que a infiltração vertical é mais importante em B3-E possivelmente devido à presença de grande quantidade de juntas colunares. No basalto denso e em profundidades maiores que $15 \mathrm{~m}$ as fraturas horizontais não estão alteradas. Por outro lado, percolação ao longo de fraturas subverticais provavelmente tectônicas, atinge profundidades de, pelo menos, 20 a $25 \mathrm{~m}$ (Figura 8). No entanto, tais fraturas com alteração intensa próxima à superfície, sejam verticais 
ou horizontais, podem não estar presentes, em grandes porções do maciço, mesmo em B3-E (Figura 3A).

A maior abertura, maior fluxo e alteração, ao longo de fraturas subverticais de origem tectônica (Figura 7), podem ser devidos a: (1) orientação favorável com relação ao campo de esforços tectônicos de um evento jovem (Quaternário) ou atual; ou (2) desconfinamento lateral para fraturas subparalelas à face de taludes. A questão do desconfinamento lateral foi abordada anteriormente por Marques Filho et al. (1981) quando observaram que falhas subverticais e juntas colunares permitem infiltração e decomposição de forma disseminada, bem mais intensa nas zonas topograficamente altas, pois abrem por descompressão, aumentando a condutividade hidráulica nas proximidades de taludes. Marques Filho et al. (1981) observaram que brechas, contatos e fraturas sub-horizontais desviam a infiltração ocasionando aprofundamento lateral da alteração rumo ao interior da encosta. Este processo dá origem à morfologia em degraus, sendo que rampas de caimento suave correspondem a contatos entre derrames e encostas com declive elevado, a níveis de basalto denso (Leinz, 1949; Marques Filho et al., 1981). A hipótese do desconfinamento lateral, controlado pela direção de talude próximo, foi avaliada para os afloramentos de Bonfim Paulista. Concluiu-se que no AF8 e no AF11, as direções N40-90E e N5-20W, respectivamente, por serem transversais aos taludes, têm sua maior permeabilidade controlada mais provavelmente por campo de esforços tectônicos. O mesmo ocorre com as fraturas subverticais de alteração profunda no AF14, de direção N50-60E e secundariamente N40W, e no AF24, direção N60E (Figuras 7A e 5D, respectivamente).

Fluxo preferencial ao longo de fraturas subverticais ENE e NNE é indicado pelas feições descritas a seguir:

1. Braço principal e secundário da Gruta Itambé (AF23), paralelo a fraturas subverticais N80E e N10E, respectivamente. Supõe-se que a ocorrência de piping (processo formador da gruta) é controlada por fluxos preferenciais ao longo daquelas direções. Na gruta também foram medidas fraturas de mergulho médio (possíveis falhas normais) de direção N20-25E, N10W e N30W. Estas possíveis falhas normais podem indicar que este local da gruta foi dominado por eventos trans-extensionais do Quaternário, mas predominou a direção ENE, supostamente paralela ao SHmax atual (ver abaixo).

2. Padrão de estruturas tectônicas em arenitos (Figura 8) exibindo conjugados de cisalhamento (N10E e N55E) e grande desenvolvimento de fraturas T (N35E), mostrando uma componente extensional importante provavelmente para o evento eNNE.

3. Fraturas N35E e N60E subverticais acompanhadas de alteração pronunciada e cortando nível vesicular da base de B3-C no AF11. Isto ocorre a profundidades de $45 \mathrm{~m}$ sob camada de B3-E não alterado, tais fraturas estão conectadas a outras sub-horizontais, por onde ocorre percolação.

4. Fraturas, em mina d'água em Araraquara (SP), de direção N15-30E e N50-70E e mergulho médio que sugere se tratarem de pequenas "falhas" normais; estas teriam sido geradas pela atuação de $\sigma 1$ de direção NE.

5. Falhas normais de direção N25E (AF7) e N50E (AF8), sugerindo que os eventos transcorrentes eENE e eNNE, aos quais as falhas devem estar relacionadas, são trans-extensionais. Por outro lado, falha inversa de direção N60W, pode ter sido gerada pelo evento eNNE, e tal direção seria mais fechada, ou menos permeável.

Assim, conclui-se que as direções NNE e ENE parecem ser caminhos preferenciais para o fluxo vertical e podem corresponder a fraturas híbridas de cisalhamento, de evento trans-extensional com $\sigma 1$ de orientação NE e próximo à direção do SHmax atual, de orientação ENE, identificado para o sul do Cráton do São Francisco (Assumpção, 1998). Este resultado não deve ser extrapolado automaticamente para outras regiões do Estado, pois, como verificado na literatura, existem variações importantes, para regiões distintas do Estado, com relação à neotectônica. Assim, análises estruturais locais são sempre recomendáveis. O fluxo vertical, cortando toda a pilha de basaltos e chegando ao SAG, deve ser de ocorrência local devido a dois fatores verificados em afloramentos: (1) zonas de fraturas subverticais não são abundantes e, (2) pelo menos as menos expressivas não devem se propagar através das camadas de $\mathrm{B}-\mathrm{VA}$, as quais apresentam poucas e/ou descontínuas fraturas subverticais, como também verificado na perfilagem acústica de poços (Figura 4). A propagação de fraturas nos B-VAs é inibida muito provavelmente pelo fato da deformação ser acomodada por pequenos deslocamentos nos limites de vesículas, amídalas e geodos. No entanto, fraturas planares (Figura 5F) ou zonas de fraturas de cisalhamento (Figura 5D), de provável origem tectônica, por vezes, cortam os níveis B-VA.

$\mathrm{Na}$ área estudada, os caminhos preferenciais de fluxo, principalmente até profundidades ao redor de $55 \mathrm{~m}$, são indubitavelmente fraturas sub-horizontais, por vezes, com extensão mínima de várias centenas de metros (Figura 3). As mais extensas foram observadas no contato B2/B3 e B3-C/B3-E e sua gênese, neste caso, é explicada pela atuação de elevada pressão de fluidos em B3, atuante mais provavelmente em locais onde B3 é menos espesso (ver item "Fraturas horizontais"). A abertura atual destas fraturas deve diminuir significativamente com o aumento da profundidade pois também é controlada por alívio de pressão devido à denudação.

O fluxo de água detectado nos poços construídos associa-se a algumas fraturas sub-horizontais ou de mergulhos 
baixos identificadas nas perfilagens acústicas (Wanhfried et al., 2010). No poço PL, ocorrem nas profundidades aproximadas de: (1) $16 \mathrm{~m}$, no B2 denso; (2) $25 \mathrm{~m}$, em fraturas de direção N23-69E com mergulhos de variam de 32 a $62^{\circ}$, também no B2 denso; (3) e ao redor de $55 \mathrm{~m}$, no B1-VA (Figura 4), em fraturas de direção N33-51E com mergulhos variando de 15 a $27^{\circ}$ para NW. No poço PG ocorrem as seguintes entradas de água associadas a fraturas sub-horizontais: em $32 \mathrm{~m}$, no arenito; em $37 \mathrm{~m}$, no contato entre arenito intertrappe e topo do B2-VA; em B1-VA na profundidade de $125 \mathrm{~m}$ (Figura 4). Todas estas fraturas em B2 e B1 parecem ser menos transmissivas que as observadas em B3 no AF11 (Figura 3), pois, segundo Wahnfried et al. (2010), as vazões a elas associadas são baixas.

Com base nas feições descritas acima foi elaborado modelo conceitual de fluxo de água subterrânea para os basaltos de Bonfim Paulista, apresentado na Figura 13. É importante notar que o modelo conceitual de fluxo nos basaltos, bem como a distribuição das fraturas subverticais, é do tipo limitado por estratos, descrito na literatura como stratabound (Odling et al., 1999). Neste tipo de modelo, cada derrame representa um estrato (à semelhança de unidades sedimentares) e a grande maioria das fraturas subverticais não se propaga nas camadas de B-VA, impedindo o fluxo vertical. Assim, o fluxo paralelo aos derrames é mais contínuo e mais intenso que o fluxo transversal a eles. Isto tem como consequência, em termos regionais, a inexistência de recarga do SAG através do ASG, ou falta de conexão entre a superfície e o SAG. Esta conexão deve ocorrer apenas localmente, onde fraturas tectônicas subverticais mais expressivas seccionam os níveis B-VA. Neste caso, o fluxo ocorreria preferencialmente ao longo de estruturas NE.

\section{CONCLUSÕES}

As fraturas horizontais apresentam comprimentos que variam de decímetros a centenas de metros e espaçamentos decimétricos a métricos. As mais extensas ocorrem nos contatos B3-C/B3-E (B3 entablamento e B3 colunada, respectivamente) e B2/B3, observadas até a profundidade de 55 m. Apresentam fluxo importante de água subterrânea e foram geradas por fraturamento hidráulico pelo aumento da pressão de fluidos após a solidificação de B3, devido ao acúmulo de fluidos residuais em determinadas porções de B3-C. A associação de fraturas de cisalhamento de baixo ângulo às fraturas horizontais (estas de maior abertura), indicam a atuação de cisalhamento e de um esforço máximo $(\sigma 1)$ horizontal, provavelmente tectônico. As suas aberturas atuais são controladas também por alívio de pressão.

Observam-se dois tipos de fraturas subverticais: de resfriamento e geradas por tectônica. As fraturas que delimitam colunas são indubitavelmente do primeiro tipo.
Já as que não delimitam são interpretadas como tectônicas quando configuram padrão de fraturas conjugadas ou quando constituem zonas de fraturas com densidades elevadas, trends predominantes (distribuição anisotrópica), e feições indicativas de cisalhamento (ex., anastomosamento). As densidades das fraturas subverticais variam de 0,04 a 4 fraturas/m; os minerais de preenchimento mais comuns, oriundos de atividade hidrotermal, são: celadonita, sílica microcristalina, zeólitas, pirita. Calcita também está presente e provavelmente se originou a partir de águas meteóricas. Os trends predominantes de fraturas tectônicas variam de afloramento para afloramento. Alguns deles foram observados em arenitos intertrappe.

Os eventos tectônicos pós-basaltos da área de estudo apresentam quatro direções principais para o esforço máximo principal $(\sigma 1)$ : N75E, N55W, NS e N30E, em ordem decrescente de idade. São parcialmente correlacionáveis aos eventos descritos na literatura para outras regiões do Estado, sendo o mais antigo ( $\sigma 1 \sim \mathrm{N} 75 \mathrm{E})$ anterior ou contemporâneo ao Neógeno e os mais jovens (N55W, NS e N30E ), do quaternário

Os eventos identificados, denominados de eENE, eNW, eNS e eNNE, são todos transcorrentes (falhas subverticais com estrias sub-horizontais ou de caimento baixo), sendo que os dois primeiros são os mais conspícuos e ambos trans-extensionais, como indicado pelos ângulos $2 \theta$ de conjugados e pela presença de fraturas extensionais associadas.

Próximo à superfície do terreno, até profundidades de $15 \mathrm{~m}$, os fluxos vertical e horizontal são intensos, como demonstrado pela alteração de fraturas, principalmente em B3. A partir de 10 a $15 \mathrm{~m}$ de profundidade o fluxo vertical é desviado por fraturas horizontais. Zonas estreitas de fraturas tectônicas permitem fluxo vertical até pelo menos 25 $\mathrm{m}$ de profundidade. A circulação de água subterrânea é limitada pelos contatos dos derrames, ou seja é do tipo stratabound, pois o fluxo preferencial ocorre ao longo de fraturas mais extensas paralelas aos estratos e próximas aos contatos entre basaltos; estas fraturas ocorrem predominantemente até a profundidade $55 \mathrm{~m}$. A grande maioria das fraturas subverticais não se propaga nas camadas de B-VA, impedindo o fluxo vertical, levando, em termos regionais, a inexistência de recarga do SAG através do ASG, ou falta de conexão entre a superfície e o SAG. Com base em feições diagnósticas de fluxo, propõe-se que o fluxo vertical, atravessando toda a pilha de basaltos e chegando ao SAG, quando presente, ocorra segundo estruturas de direção NE.

\section{AGRADECIMENTOS}

Este trabalho foi financiado pela FAPESP, na forma de um projeto de auxílio à pesquisa (processo número 
04/11798-4, projeto FRATASG coordenado pela Dra. Amélia João Fernandes), de uma bolsa de doutorado (processo número 04/15543-0, doutorando Ingo Wahnfried) e de uma bolsa de iniciação científica (processo número 2005/00101-5, aluno de graduação Carlos Henrique Maldaner). A coordenação do projeto esteve a cargo do Instituto Geológico - SMASP e o apoio de infra-estrutura, a cargo do Laboratório de Modelos Físicos (LAMO) - IGc/USP e do Instituto Geológico - SMASP. Agradecimentos são estendidos aos colegas José Maria Azevedo Sobrinho e Francisco de Assis Negri, do Instituto Geológico, pelo apoio na análise de lâminas petrográficas, e a todos os componentes da equipe do projeto FRATASG, pelo acompanhamento nos trabalhos de campo.

\section{REFERÊNCIAS}

ANGELIER, J. Fault slip analysis and palaeostress reconstruction. In: HANCOCK, P. L. (Ed.). Continental Deformation. Oxford: Pergamon Press, 1994. p. 53-100.

ANGELIER, J.; MECHLER, P. Sur une methode grafique de recherche des constraintes principales également utilisable en tectonique et en seismologie: la methode des diedres droits. Bulletin Societe Geologique de France. v. 7, p. 1309-1318, 1977.

ASSUMPÇÃO, M. Focal mechanisms of small earthquakes in the southeastern Brazilian shield: a test of stress models of the South American Plate. Geophysical Journal International, v. 133, p. 490-498, 1998.

BJORNBERG, A. J. S.; KUTNER, A. S. Resumo das feições geológicas de interesse às fundações em rocha, em barragens da Bacia do Alto Paraná. In: SIMPÓSIO SOBRE A GEOTECNIA DA BACIA DO ALTO PARANÁ,1983, São Paulo. Anais... São Paulo: ABMS/ABGE/CBMR, v. 1A, 1983. p. 263-297.

BUDKEWITSCH, P.; ROBIN, P. Y. Modelling the evolution of columnar joints. Journal of Volcanology and Geothermal Research, v. 59, n. 33, p. 219-239, 1994.

DUNNE,W. M.; HANCOCK, P. L. Palaeostress analysis of small-scale brittle structures. In: HANCOCK, P. L. (Ed.). Continental Deformation. Oxford: Pergamon Press, 1994. p. 101-120.

FERNANDES, A. J.; AMARAL, G. Cenozoic tectonic events at the border of the Parana Basin, São Paulo, Brazil. Journal of South American Earth Sciences. v. 14, n. 8, p. 911-931, 2002.
FERNANDES, A. J.; MALDANER, C. H.; SOBRINHO, J. M. A.; PRESSINOTTI, M. M. N.; WAHNFRIED, I. Estratigrafia dos Derrames de Basaltos da Formação Serra Geral (Ribeirão Preto - SP) Baseada na Geologia Física, Petrografia e Geoquímica. Geologia USP. Série Cientifica, São Paulo, v. 10, n. 2, p. 73-99, 2010.

FERNANDES, A. J.; MALDANER, C.; WAHNFRIED, I.; FERREIRA, L. M. R.; PRESSINOTTI, M.; VARNIER, C.; IRITANI, M. A.; HIRATA, R. Modelo conceitual preliminar de circulação de água subterrânea do Aquífero Serra Geral, Ribeirão Preto, SP In: CONGRESSO BRASILEIRO DE ÁGUAS SUBTERRÂNEAS, 14., 2006, Curitiba. Anais... Curitiba: ABAS, 2006. 16 p. CD ROM.

FERNANDES, A. J.; MELLO, C. L. Coberturas cenozóicas e estruturas deformadoras na Depressão Periférica Paulista, Campinas, São Paulo. Revista do Instituto Geológico. São Paulo, v. 25, p. 49 - 66, 2004.

FERNANDES, A. J.; ROULEAU, A. Simulação de deslocamentos em fraturas em basaltos da Formação Serra Geral (Ribeirão Preto, SP) e implicações para a sua transmissividade. In: CONGRESSO BRASILEIRO DE ÁGUA SUBTERRÂNEA, 15., 2008, Natal. Anais... Natal: ABAS, 2008. CD-ROM.

FRANK, H. T.; WAICHEL, B. L.; GOMES, M. E. B.; FORMOSO, M. L. L. Carbonatos de Mg, Fe e Mn e outros minerais secundários de um derrame de lava basáltico da Formação Serra Geral (Bacia do Paraná, América do Sul): descrição e seqüência de cristalização. In: SIMPÓSIO DE VULCANISMO E AMBIENTES ASSOCIADOS, 4., 2008, Foz do Iguaçu. Anais... Foz do Iguaçu: SBG, 2008. 6 p. CD ROM.

HIRUMA, S. T.; RICCOMINI, C.; MODENESIGAUTTIERI, M. C. Neotectônica no Planalto de Campos do Jordão, SP. Revista Brasileira de Geociências. v. 31, n. 3, p. 375-384, 2001.

JERRAM, D.; STOLLHOFEN, H. Lava-sediment interaction in the desert settings; are all peperite-like textures the result of magma-water interaction? Journal of Volcanology and Geothermal Research. v. 114, p. 231-249, 2002.

LEINZ, V. Contribuição à geologia dos derrames basálticos do sul do Brasil. Boletim da Faculdade de Filosofia, Letras e Ciências Humanas da Universidade de São Paulo. Geologia 5, v. 103, p. 1-67, 1949. 
LONG, P. E.; WOOD, B. J. Structures, textures, and cooling histories of Columbia River basalt flows. Geological Society of America Bulletin, v. 97, n. 9, p. 1144-1155, 1986.

MARQUES, D. J.; MAGALHÃES， F. S.; SERRA JÚNIOR, E. Análise das feições estruturais do maciço rochoso nas fundações da barragem de Porto Primavera. In: CONGRESSO BRASILEIRO DE GEOLOGIA DE ENGENHARIA, 5., 1987, São Paulo. Anais... São Paulo: ABGE, 1987. v. 1, p. 197-209.

MARQUES FILHO, P. L.; CORREIA, P. C.; LEVIS, P.; ANDRADE, C. A. V. Características usuais e aspectos peculiares do manto de alteração e transição solo-rocha em basaltos. In: CONGRESSO BRASILEIRO DE GEOLOGIA DE ENGENHARIA, 3., 1981, Itapema. Anais... Itapema: SG, ABGE, 1981, v. 2, p. 53-72.

MICHELIN, C. R. L.; HARTMANN, L. A.; PIRES, C. A. F.; ROSENTENSTEGEL, L. M. Seqüência de formação das cavidades no basalto e seu preenchimento com zeolitas, arenito, ágata e ametista, São Martinho da Serra, Rio Grande do Sul, Brasil. In: SIMPÓSIO DE VULCANISMO E AMBIENTES ASSOCIADOS, 4., 2008, Foz do Iguaçu. Anais... Foz do Iguaçu: SBG, 2008. 6 p. CD ROM.

ODLING, N. E.; GILlESPIE, P.; BOURGINE, B.; CASTAING, C.; CHLES, J. P.; CHRISTENSEN, N. P.; FILLION, E.; GENTER, A.; OLSEN, C.; THRANE, L.; TRICE, R.; AARSETH, E.; WALSH, J. J.; WATTERSON, J. Variations in fracture system geometry and their implications for fluid flow in fractured hydrocarbon reservoirs. Petroleum Geoscience, v. 5, p. 373-384, 1999.

PETIT, J. P. Criteria for the sense of movement on fault surfaces in brittle rocks. Journal of Structural Geology. v. 9, n. 5-6, p. 597-608, 1987.

PRICE, N. J.; COSGROVE, J. W. Analysis of geological structures. Cambridge: Cambridge University Press, 1990. 502 p.

ROULEAU, A.; GALE, J. E. Characterizing Orientation, Spacing and Lenth of Fractures for Hydrogeological Purposes: Application to the Gneissic Bedrock at Chalk River. Report to Atomic Energy of Canada Limited, University of Waterloo Research Institute, 1981. 153 p.

RICCOMINI, C. Considerações sobre a posição estratigráfica e tectonismo deformador da Formação
Itaqueri na porção centro-leste do Estado de São Paulo. Revista do Instituto Geológico, São Paulo, v. 18, n. 1-2, p. 41-48, 1997.

SALVADOR, E. D.; RICCOMINI, C. Neotectônica da Região do Alto Estrutural de Queluz (SP-RJ, Brasil). Revista Brasileira de Geociências. v. 25, p. 151-164, 1995.

SELF, S.; KESZTHELYI, L.; THORDARSON, T. The importance of pahoehoe. Annual Review of Earth Planetary Sciences, v. 26, p. 81-110, 1998.

WAHNFRIED, I.; FERNANDES, A. J.; HIRATA, R.; MALDANER, C.; VARNIER, C. L.; FERREIRA, L. M. R.; IRITANI, M. A.; PRESSINOTTI, M. M. N. Anisotropia e Confinamento Hidráulico do Sistema Aquífero Guarani em Ribeirão Preto (SP, Brasil). In: CONGRESSO BRASILEIRO DE ÁGUAS SUBTERRÂNEAS, 16., 2010, São Luis. Anais... São Luis: ABAS, 2010. CD-ROM. 